\title{
Challenges and Advancement of Blue III-Nitride Vertical-Cavity Surface-Emitting Lasers
}

\author{
Chia-Yen Huang *D, Kuo-Bin Hong, Zhen-Ting Huang, Wen-Hsuan Hsieh, Wei-Hao Huang and Tien-Chang Lu * \\ Department of Photonics, College of Electrical and Computer Engineering, National Yang Ming Chiao Tung \\ University, Hsinchu 30010, Taiwan; kbhong@nctu.edu.tw (K.-B.H.); psgchsfmax8@gmail.com (Z.-T.H.); \\ clock1597531@gmail.com (W.-H.H.); winjr10595@gmail.com (W.-H.H.) \\ * Correspondence: cyhuang06@nycu.edu.tw (C.-Y.H.); timtclu@mail.nctu.edu.tw (T.-C.L.)
}

Citation: Huang, C.-Y.; Hong, K.-B.; Huang, Z.-T.; Hsieh, W.-H.; Huang, W.-H.; Lu, T.-C. Challenges and Advancement of Blue III-Nitride Vertical-Cavity Surface-Emitting Lasers. Micromachines 2021, 12, 676. https://doi.org/10.3390/mi12060676

Academic Editors: Shyh-Chiang Shen, Chien-Chung Lin and Chao-Hsin Wu

Received: 26 April 2021

Accepted: 4 June 2021

Published: 9 June 2021

Publisher's Note: MDPI stays neutral with regard to jurisdictional claims in published maps and institutional affiliations.

Copyright: (c) 2021 by the authors. Licensee MDPI, Basel, Switzerland. This article is an open access article distributed under the terms and conditions of the Creative Commons Attribution (CC BY) license (https:// creativecommons.org/licenses/by/ $4.0 /)$.

\begin{abstract}
Since the first demonstration of (Al, In, Ga)N-based blue vertical-cavity surface-emitting lasers (VCSELs) in 2008, the maximum output power $\left(\mathrm{P}_{\max }\right)$ and threshold current density $\left(\mathrm{J}_{\mathrm{th}}\right)$ has been improved significantly after a decade of technology advancements. This article reviewed the key challenges for the realization of VCSELs with III-nitride materials, such as inherent polarization effects, difficulties in distributed Bragg's reflectors (DBR) fabrication for a resonant cavity, and the anti-guiding effect due to the deposited dielectrics current aperture. The significant tensile strain between AIN and GaN hampered the intuitive cavity design with two epitaxial DBRs from arsenidebased VCSELs. Therefore, many alternative cavity structures and processing technologies were developed; for example, lattice-matched AlInN/GaN DBR, nano-porous DBR, or double dielectric DBRs via various overgrowth or film transfer processing strategies. The anti-guiding effect was overcome by integrating a fully planar or slightly convex DBR as one of the reflectors. Special designs to limit the emission polarization in a circular aperture were also summarized. Growing VCSELs on low-symmetry non-polar and semipolar planes discriminates the optical gain along different crystal orientations. A deliberately designed high-contrast grating could differentiate the reflectivity between the transverse-electric field and transverse-magnetic field, which restricts the lasing mode to be the one with the higher reflectivity. In the future, the III-nitride based VCSEL shall keep advancing in total power, applicable spectral region, and ultra-low threshold pumping density with the novel device structure design and processing technologies.
\end{abstract}

Keywords: GaN; III-nitrides; VCSEL; distributed Bragg reflector; carrier aperture; polarization

\section{Introduction}

(Al,Ga,In)N-based laser diodes (LD) have been used in optical storage, signage, projector display, industrial manufacturing, and many other applications. The realization of III-nitride-based LDs comes much later than other arsenide- and phosphide-based LDs although they shared similar device design concepts. InGaN/GaN-based LDs were firstly demonstrated in the early 90's after Dr. Shuji Nakamura achieved breakthroughs in epitaxial technologies [1-3]. Later in 90's, the development of low threading dislocation GaN substrates further boosted the performance of nitride-based LDs [4-7]. To date, low-threshold $\left(\mathrm{J}_{\mathrm{th}}<2 \mathrm{kA} / \mathrm{cm}^{2}\right)$ and state-of-art high-power $(\mathrm{P}>10 \mathrm{Watt})$ edge-emitting lasers (EEL) have been demonstrated [8-10]. III-nitride vertical-cavity surface-emitting lasers (VCSELs) arrived even later. Electrically pumped III-nitride VCSELs were firstly demonstrated by NCTU and Nichia Corp., Tokushima, Japan, with different device configurations in 2008, which was more than a decade later than the EELs [11,12]. The late arrival of III-nitride VCSELs can be attributed to the inherent challenges from the nitride materials' properties. Although some challenges were also encountered by EELs, the influences are more significant for VCSELs.

Wurtzite III-nitrides (as shown in Figure 1a) is a piezoelectric material family with distinctive differences in fundamental material parameters. Although the spontaneous 
polarization $\left(\mathrm{P}_{\mathrm{sp}}\right)$ all points toward the $\mathrm{N}$-polar surface, the final polarization was mostly dominated by its piezoelectric polarization $\left(\mathrm{P}_{\mathrm{pz}}\right)$ :

$$
\begin{gathered}
P_{p z}=2\left(e_{31}-e_{33} \frac{C_{13}}{C_{33}}\right) * \varepsilon \\
\varepsilon=\frac{a_{f}-a_{0}}{a_{0}}
\end{gathered}
$$

where $e_{31}$ and $e_{33}$ are piezoelectric tensor elements, $C_{13}$ and $C_{33}$ are elastic constants, $\varepsilon$ is the strain state of materials, $\mathrm{a}_{\mathrm{f}}$ and $\mathrm{a}_{0}$ is the lattice constant in the film and in the bulk crysl, respectively. The values of the above parameters are summarized in Table 1 [13-17]. Since the bracket in Equation (1) is always negative, the $\mathrm{P}_{\mathrm{pz}}$ is determined by the sign of $\varepsilon$. For AlGaN alloys on GaN template, $\varepsilon>0$ (tensile strain) and $\mathrm{P}_{\mathrm{pz}}$ is parallel to the $\mathrm{P}_{\mathrm{sp}}$; for InGaN alloys, $\varepsilon<0$ (compressive strain) and $\mathrm{p}_{\mathrm{pz}}$ are antiparallel to the $\mathrm{P}_{\mathrm{sp}}$. The total polarization is the sum of $\mathrm{P}_{\mathrm{sp}}$ and $\mathrm{P}_{\mathrm{pz}}$. As a result, every layer in the epi structure possesses different polarizations. The discontinuity of polarization induces sheet charges at interfaces and a zig-zag profile in a band diagram, as illustrated in Figure 1b. The zig-zag band profile lowered the overlapping between wavefunctions in the conduction band and valance band, so the transition matrix elements in the quantum well are also reduced. The wavefunction overlapping in an undoped $3 \mathrm{~nm} \operatorname{In}_{0.2} \mathrm{Ga}_{0.8} \mathrm{~N} / \mathrm{GaN}$ quantum well is only $\sim 0.15$ under equilibrium, and still $<0.4$ under a $1 \mathrm{kA} / \mathrm{cm}^{-2}$ current injection [18]. Fortunately, the high density-of-state of III-nitrides compensated the effects of the low transition matrix element in the maximum optical gain $\left(\mathrm{g}_{\max }\right)$. The tolerable internal and scattering losses of III-nitride VCSELs are no less than those made with arsenide- or phosphide-based materials $[19,20]$. With the same level of optical losses in the device, the $J_{\text {th }}$ of nitride-based VCSELs is inevitably higher. Figure 2 benchmarks the maximum output power $\left(\mathrm{P}_{\max }\right)$ and the $\mathrm{J}_{\text {th }}$ performance from literature in chronological order [21-53]. Representative device structures such as reflector types, cavity lengths, and aperture design were summarized in Table 2. From 2008 to 2020, the $P_{\max }$ has been enhanced about 100 folds for a single VCSEL, but the $\mathrm{J}_{\text {th }}$ remained $\sim 10 \mathrm{kA} / \mathrm{cm}^{-2}$. The relatively limited $\mathrm{J}_{\text {th }}$ improvement might be also attributed to the high density of the state of III-nitride materials and the relatively short gain path in the cavity. As references, the representative $\mathrm{J}_{\text {th }}\left(\mathrm{P}_{\max }\right)$ was $0.9 \mathrm{kA} / \mathrm{cm}^{2}(9 \mathrm{~mW})$ for $850 \mathrm{~nm}$ GaAs-based VCSELs, $0.8 \sim 1.7 \mathrm{kA} / \mathrm{cm}^{2}(7.7 \sim 11 \mathrm{~mW})$ for $940 \mathrm{~nm} \sim 980 \mathrm{~nm}$ GaAsbased VCSELs, $3.1 \mathrm{kA} / \mathrm{cm}^{2}(3.6 \mathrm{~mW})$ for $1.3 \mu \mathrm{m}$ GaAs-based VCSEL, and $3.5 \mathrm{kA} / \mathrm{cm}^{2}$ (3.0 $\mathrm{mW})$ for $1.55 \mu \mathrm{m}$ for InP-based VCSELs [54-58].

(a)

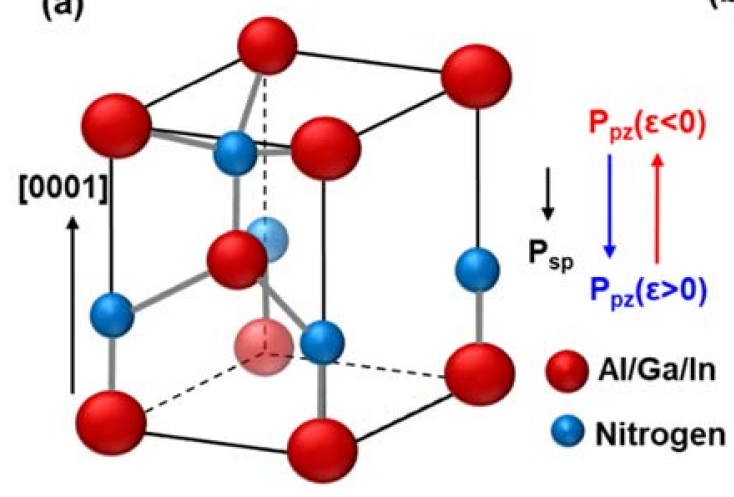

(b)

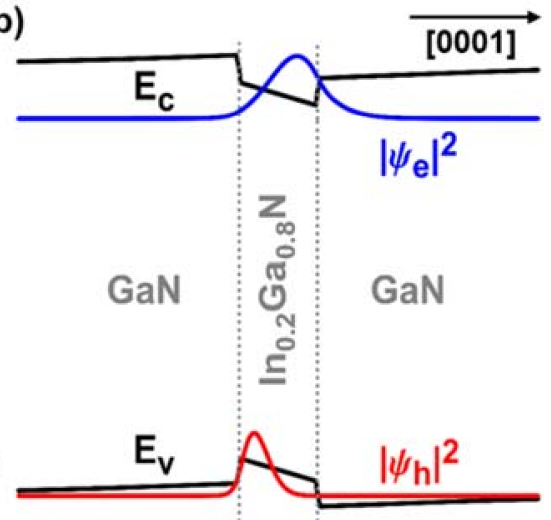

Figure 1. (a) Schematic Wurtzite nitride structure and the direction of spontaneous polarization $\left(\mathrm{P}_{\mathrm{sp}}\right)$ and piezoelectric polarization $\left(\mathrm{P}_{\mathrm{pz}}\right)$. (b) Band diagram of undoped $3 \mathrm{~nm} \mathrm{GaN} / \mathrm{In}_{0.2} \mathrm{Ga}_{0.8} \mathrm{~N} / \mathrm{GaN}$ quantum-well grown along c-axis with wavefunctions in a ground state. 
Table 1. The lattice constant, spontaneous polarization, piezoelectric tensor elements, elastic constant, electron effective masses, and of wurtzite nitride materials. Parameters collected from references [13-17].

\begin{tabular}{cccc}
\hline & AlN & GaN & InN \\
\hline $\mathrm{a}_{0}(\AA)$ & 3.112 & 3.186 & 3.548 \\
$\mathrm{c}_{0}(\AA)$ & 4.982 & 5.186 & 5.703 \\
$\varepsilon_{\mathrm{x}}$ to $\mathrm{GaN}(\%)$ & 2.47 & - & -10.20 \\
$\varepsilon_{\mathrm{z}}$ to $\mathrm{GaN}(\%)$ & 4.07 & - & -9.07 \\
$\mathrm{P}_{\mathrm{sp}}\left(\mathrm{C} / \mathrm{m}^{2}\right)$ & -0.081 & -0.029 & -0.032 \\
$\mathrm{e}_{31}\left(\mathrm{C} / \mathrm{m}^{2}\right)$ & 1.46 & 0.73 & 0.97 \\
$\mathrm{e}_{33}\left(\mathrm{C} / \mathrm{m}^{2}\right)$ & -0.60 & -0.49 & -0.57 \\
$\mathrm{C}_{13}(\mathrm{GPa})$ & 108 & 103 & 92 \\
$\mathrm{C}_{33}(\mathrm{GPa})$ & 373 & 405 & 224 \\
$\mathrm{~m}_{\mathrm{e}} / \mathrm{m}_{0}$ & 0.4 & 0.2 & 0.11 \\
\hline
\end{tabular}
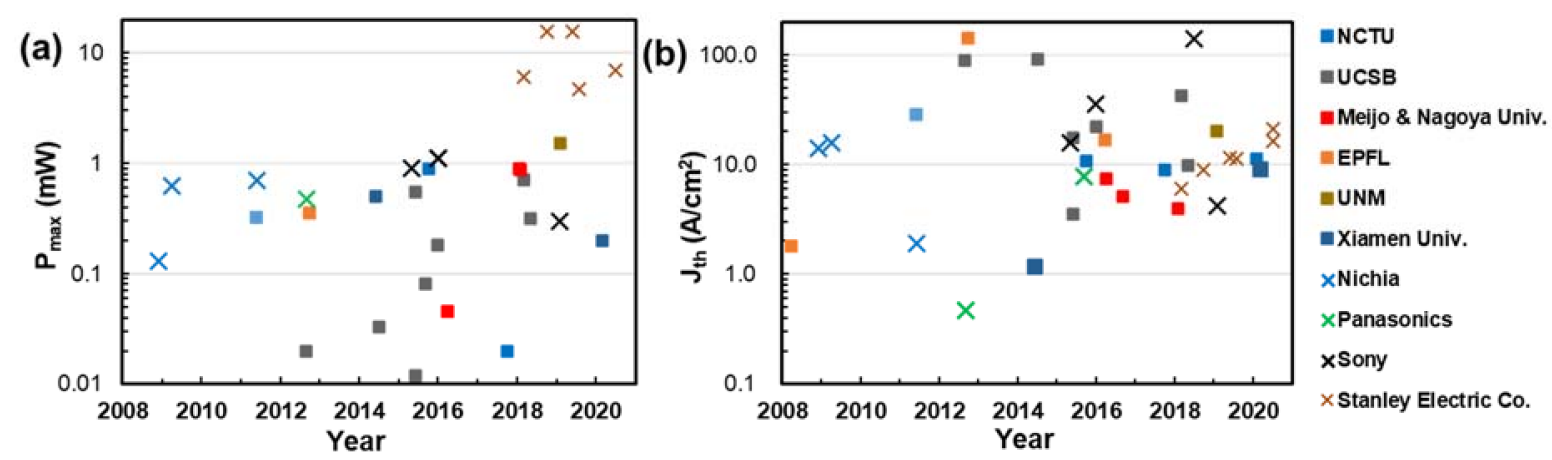

Figure 2. Benchmarks of (a) maximum output power $\left(\mathrm{P}_{\max }\right)$ and $(\mathbf{b})$ threshold current density $\left(\mathrm{J}_{\mathrm{th}}\right)$ of electrically pumped nitride blue VCSELs in chronological order of publication. Device parameters were extracted from references [11,12,21-53]. 


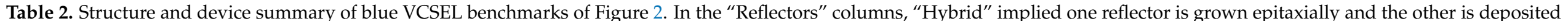

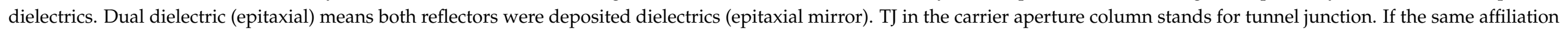

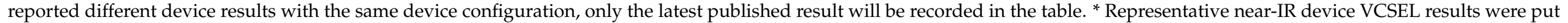
at the bottom of the table. For a more compact table, the spectral region is recorded in the affiliation column.

\begin{tabular}{|c|c|c|c|c|c|c|c|}
\hline Affiliation & Reflectors & Cavity Length & Carrier Aperture & $\begin{array}{c}J_{\text {th }} \\
\left(\mathrm{kA} / \mathrm{cm}^{2}\right)\end{array}$ & $\begin{array}{l}P_{\max } \\
(\mathrm{mW})\end{array}$ & Operating Condition & Ref. \\
\hline NCTU, & $\begin{array}{c}\text { Hybrid } \\
(\mathrm{AlN} / \mathrm{GaN})\end{array}$ & $5 \lambda$ & \multirow{2}{*}{ Flat $\mathrm{SiO}_{2}$} & 10.6 & 0.9 & $\mathrm{CW} / \mathrm{RT}$ & {$[12,27,28]$} \\
\hline $\begin{array}{l}\text { Hsinchu, } \\
\text { Taiwan }\end{array}$ & $\begin{array}{l}\text { Dual dielectric } \\
\text { Dielectric + HCG }\end{array}$ & $\begin{array}{c}2.5 \lambda \\
5 \lambda\end{array}$ & & $\begin{array}{c}8.9 \\
11.2\end{array}$ & $\begin{array}{c}0.02 \\
0.007\end{array}$ & $\begin{array}{c}\text { Pulse/350 K } \\
\text { Pulse/RT }\end{array}$ & $\begin{array}{c}{[29,30]} \\
{[31]}\end{array}$ \\
\hline $\begin{array}{l}\text { Nichia Corp., Tokushima, } \\
\text { Japan }\end{array}$ & Dual dielectric & $7 \lambda$ & Flat $\mathrm{SiO}_{2}$ & 1.9 & 0.7 & $\mathrm{CW} / \mathrm{RT}$ & {$[11,32,33]$} \\
\hline $\begin{array}{l}\text { Sony Corp., Kanagawa, } \\
\text { Japan }\end{array}$ & Dual dielectric & $\begin{array}{c}10 \lambda \\
\sim 150 \mu \mathrm{m}\end{array}$ & $\begin{array}{l}\text { Flat } \mathrm{SiO}_{2} \\
\text { Implanted B }\end{array}$ & $\begin{array}{c}15.9 \\
4.2\end{array}$ & $\begin{array}{l}0.9 \\
0.3 \\
\end{array}$ & $\mathrm{CW} / \mathrm{RT}$ & $\begin{array}{l}{[35,36]} \\
{[37,38]}\end{array}$ \\
\hline $\begin{array}{l}\text { Panasonic Corp. } \\
\text { Kyoto, Japan }\end{array}$ & Dual dielectric & $30 \lambda$ & Flat $\mathrm{SiO}_{2}$ & 0.5 & 0.003 & $\mathrm{CW} / \mathrm{RT}$ & [34] \\
\hline $\begin{array}{c}\text { EPFL, } \\
\text { Lausanne, Swiss }\end{array}$ & $\begin{array}{c}\text { Hybrid } \\
\text { (AlInN/GaN) }\end{array}$ & $7 \lambda$ & RIE passivation & 139.3 & 0.35 & $\mathrm{CW} / \mathrm{RT}$ & [21] \\
\hline $\begin{array}{l}\text { Meijo Univ. \& Nagoya Univ., } \\
\text { Nagoya, Japan }\end{array}$ & $\begin{array}{c}\text { Hybrid } \\
(\text { AlInN/GaN) }\end{array}$ & $1.5 \lambda \sim 4.5 \lambda$ & Flat $\mathrm{SiO}_{2}$ & 4.0 & 0.88 & $\mathrm{CW} / \mathrm{RT}$ & [22-26] \\
\hline Stanley Electric Corp. Tokyo, Japan & $\begin{array}{c}\text { Hybrid } \\
\text { (AlInN/GaN) }\end{array}$ & $\begin{array}{c}4.5 \lambda \sim 10 \lambda \\
10 \lambda\end{array}$ & $\begin{array}{l}\text { Buried } \mathrm{SiO}_{2} \\
\text { RIE passivation }\end{array}$ & $\begin{array}{l}11.6 \\
21.3\end{array}$ & $\begin{array}{l}15.7 \\
23.7\end{array}$ & $\begin{array}{l}\mathrm{CW} / \mathrm{RT} \\
\mathrm{CW} / \mathrm{RT}\end{array}$ & $\begin{array}{c}{[39-42]} \\
{[43]}\end{array}$ \\
\hline $\begin{array}{c}\text { Univ. of California, Santa Barbara, } \\
\text { CA, USA }\end{array}$ & Dual dielectric & $\begin{array}{c}7.5 \lambda \\
7 \lambda \\
7 \lambda \\
7 \lambda \\
6.5 \lambda \sim 23 \lambda\end{array}$ & $\begin{array}{c}\text { Flat } \mathrm{SiN}_{\mathrm{x}} \\
\text { Implanted } \mathrm{Al} \\
\mathrm{Ta}_{2} \mathrm{O}_{5} \text { with } \mathrm{TJ} \\
\text { PEC air-gap } \\
\text { Implanted } \mathrm{Al}\end{array}$ & $\begin{array}{c}90.9 \\
17.7 \\
3.5 \\
22.0 \\
9.7\end{array}$ & $\begin{array}{c}0.019 \\
0.012 \\
0.55 \\
0.18 \\
0.319\end{array}$ & Pulse/RT & $\begin{array}{c}{[44]} \\
{[45]} \\
{[46]} \\
{[47,48]} \\
{[49,50]}\end{array}$ \\
\hline $\begin{array}{l}\text { Univ. of New Mexico Albuquerque, } \\
\text { NM, USA }\end{array}$ & $\begin{array}{c}\text { Hybrid (GaN/ } \\
\text { nano-porous GaN) }\end{array}$ & $8 \lambda$ & Implanted $\mathrm{Al}$ with $\mathrm{TJ}$ & 20.0 & 1.5 & Pulse/RT & [51] \\
\hline $\begin{array}{c}\text { Xiamen Univ., } \\
\text { Xiamen, China } \\
\end{array}$ & Dual dielectrics & $\begin{array}{l}\text { NA } \\
2.5 \lambda\end{array}$ & $\begin{array}{c}\text { Flat } \mathrm{SiO}_{2} \\
\text { Buried } \mathrm{SiO}_{2} \\
\end{array}$ & $\begin{array}{l}1.2 \\
9.1 \\
\end{array}$ & $\begin{array}{l}0.5 \\
0.2 \\
\end{array}$ & $\mathrm{CW} / \mathrm{RT}$ & $\begin{array}{l}{[52]} \\
{[53]}\end{array}$ \\
\hline $\begin{array}{l}* 850 \mathrm{~nm} \\
940 \mathrm{~nm} \\
980 \mathrm{~nm}\end{array}$ & \multirow[t]{2}{*}{ Dual epitaxial } & $\begin{array}{c}\text { NA } \\
\text { NA } \\
0.5 \lambda\end{array}$ & $\mathrm{Al}_{\mathrm{x}} \mathrm{O}_{\mathrm{y}}$ oxide & $\begin{array}{l}0.9 \\
1.7 \\
0.8\end{array}$ & $\begin{array}{c}9 \\
7.7 \\
11\end{array}$ & \multirow[t]{3}{*}{ CW/RT } & $\begin{array}{l}{[54]} \\
{[55]} \\
{[56]}\end{array}$ \\
\hline $1310 \mathrm{~nm}$ & & $2.5 \lambda$ & TJ & 3.1 & 3.6 & & [57] \\
\hline $1550 \mathrm{~nm}$ & Dual dielectric & $2.5 \lambda$ & & 3.5 & 3.0 & & [58] \\
\hline
\end{tabular}


Besides the strain-induced polarizations and relevant quantum confinement Stark effects (QCSE), the large lattice strain between AlN and GaN itself hampered the realization of nitride VCSELs. Unlike the AlAs is nearly strain-free on GaAs, AlN on GaN suffers from a $2.47 \%$ tensile strain. Therefore, nitride-based VCSEL could not afford a double epitaxial distributed Bragg's reflector (DBR) mirrors as arsenide-based VCSELs do. In fact, growing a single AlN/GaN DBR with high reflectivity is particularly challenging. The low refractive index contrast further enhances the required total thickness for a high-reflectivity DBR. Table 3 summarized the refractive indices of $\mathrm{AlN}, \mathrm{GaN}, \mathrm{Al}_{0.82} \mathrm{In}_{0.12} \mathrm{~N}, \mathrm{Al}_{0.6} \mathrm{Ga}_{0.4} \mathrm{~N}$, and other reported dielectrics for nitride VCSELs at $420 \mathrm{~nm}$ [59-62]. We assumed a perfect Braggs condition at $\lambda_{\mathrm{B}}=420 \mathrm{~nm}$ under room temperature and neglect the index dispersion. The reflectance $(R)$ and stop-band width $\left(\Delta \lambda_{\text {stop }}\right)$ can be calculated by:

$$
\begin{gathered}
R=\left[\frac{n_{2}^{2 m}-n_{1}^{2 m}{ }^{2}}{n_{2}^{2 m}+n_{1}^{2 m}}\right] \\
\Delta \lambda_{\text {stop }}=\frac{4 \lambda_{B}}{\pi} \arcsin \left(\frac{n_{2}-n_{1}}{n_{2}+n_{1}}\right)
\end{gathered}
$$

$n_{2}$ is the high refractive index in the DBR pair, which is usually the index of GaN in epitaxial DBRs; $\mathrm{n}_{1}$ is the low refractive index, which is usually the index of $\mathrm{SiO}_{2}$ in dielectric DBRs, and $\mathrm{m}$ is the number of pairs. To achieve $R>99 \%$, the minimum $\mathrm{m}$ can be estimated by Equation (3). The corresponding $\Delta \lambda_{\text {stop }}$, total thickness, and representative reflectivity spectrum are plotted in Figure 3. Apparently, the epitaxial DBR possessed a lower bandwidth and a higher total thickness, which imposes a stringent criterion for strain management (except for the $\mathrm{Al}_{0.82} \mathrm{In}_{0.12} \mathrm{~N} / \mathrm{GaN} \mathrm{DBR}$, which is the lattice-matched condition). As a result, current nitride VCSELs adopted either one (hybrid-type) or none (dual-dielectric type) epitaxial mirrors as reflectors. Each approach also encountered its own difficulties in the fabrication process.

Table 3. The refractive constants of common materials used in nitride VCSELs. Parameters collected from references [59-62].

\begin{tabular}{ccccccc}
\hline Dielectric DBR & $\mathbf{S i O}_{\mathbf{2}}$ & $\mathrm{SiN}_{\mathbf{x}}$ & $\mathrm{Ta}_{\mathbf{2}} \mathbf{O}_{\mathbf{5}}$ & $\mathbf{Z r O}_{\mathbf{2}}$ & $\mathrm{TiO}_{\mathbf{2}}$ & $\mathbf{N b}_{\mathbf{2}} \mathbf{O}_{\mathbf{5}}$ \\
\hline $\mathrm{n}$ at $420 \mathrm{~nm}$ & 1.468 & 1.956 & 2.228 & 2.211 & 2.294 & 2.501 \\
\hline Epitaxial DBR & $\mathrm{GaN}$ & $\mathbf{A l}_{\mathbf{0 . 6}} \mathbf{G a}_{\mathbf{0 . 4}} \mathbf{N}$ & $\mathbf{A l}_{\mathbf{0 . 8 2}} \mathbf{I n}_{\mathbf{0 . 1 8}} \mathbf{N}$ & \multicolumn{2}{c}{$\mathrm{AlN}$} \\
\hline n at $420 \mathrm{~nm}$ & 2.545 & 2.255 & 2.135 & \multicolumn{2}{c}{2.096} \\
\hline
\end{tabular}
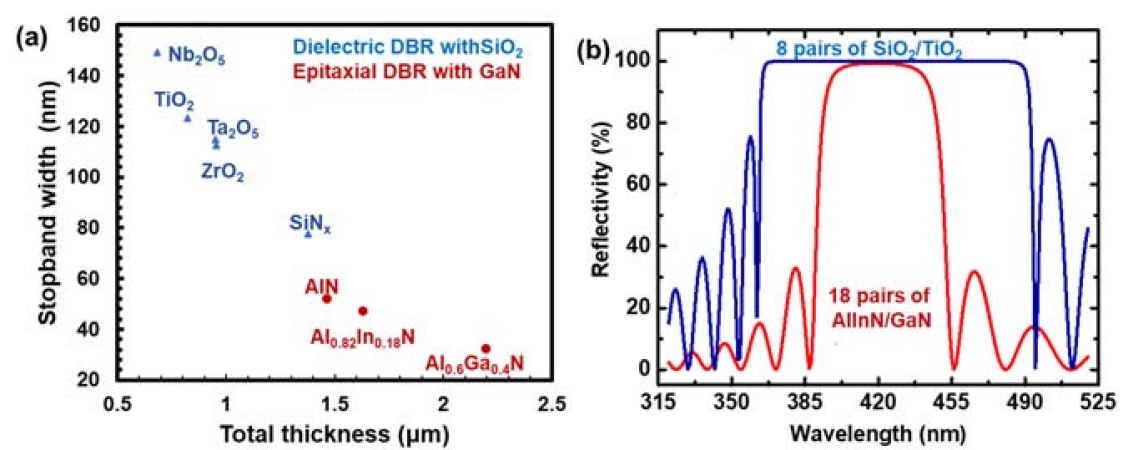

Figure 3. (a) Scatter plot of stopband width and a total thickness of ideal epitaxial and dielectric DBRs with $\mathrm{R}>0.99$ (b) Calculated reflectivity spectrum of selected DBRs.

Besides, AlGaN in III-nitride VCSELs cannot be easily oxidized to form a carrier aperture as AlGaAs could. The ion implantation process was neither a common process for III-nitride in the beginning. As a result, researchers deposited dielectric (usually $\mathrm{SiO}_{2}$ ) on the bare epitaxial wafer as the carrier aperture. However, the parasitic anti-guiding 
effect in the lateral direction was not addressed until 2014 [58,59]. Figure 4a schematically illustrated the origin of additional scattering loss due to the dielectric aperture. Assuming the total thickness between two DBR mirrors to be $L$ in the aperture region (including nitride epi and ITO contact), the total thickness in the cladding region is $L+\Delta$, where $\Delta$ is the dielectric layer thickness. The k-vectors of standing-wave in the Fabry-Perot cavity gives:

$$
\begin{aligned}
k_{a} & =\frac{m \pi}{L} \\
k_{c} & =\frac{m \pi}{L+\Delta}
\end{aligned}
$$

where $m$ is the mode number. Since $\Delta<<\mathrm{L}$, we can reasonably assume that $m$ is the same integer in both regions and $k_{a}>k_{c}$. Therefore, while constructing the propagation mode with a common effective mode propagating constant $\left(\beta_{\text {eff }}\right)$, the oblique angle of the k-vector in the aperture region will be larger than that in the cladding region. As a result, the optical energy will be constantly leaking out of the cavity in the lateral direction during oscillation, which is also known as the anti-guiding effect. The anti-guiding effect is more significant for high-order linear polarized (LP) modes due to a smaller $\beta_{\text {eff }}$, as simulated in Figure $4 \mathrm{~b}$. The anti-guiding effect causes a prevailing fundamental mode $\left(\mathrm{LP}_{01}\right)$ from other high-order modes, which might be desired for some applications, but the device performance such as $\mathrm{J}_{\text {th }}$ and $\mathrm{P}_{\max }$ will be limited. According to Hashemi et al.'s analysis, the lateral anti-guiding effect contributes $\sim 50 \%$ of total modal loss for fundamental $\mathrm{LP}_{01}$ mode and $\sim 70 \%$ of total modal loss for $\mathrm{LP}_{11}$ mode [63]. In other words, the threshold modal gain is increased at least two-fold due to the dielectric aperture.
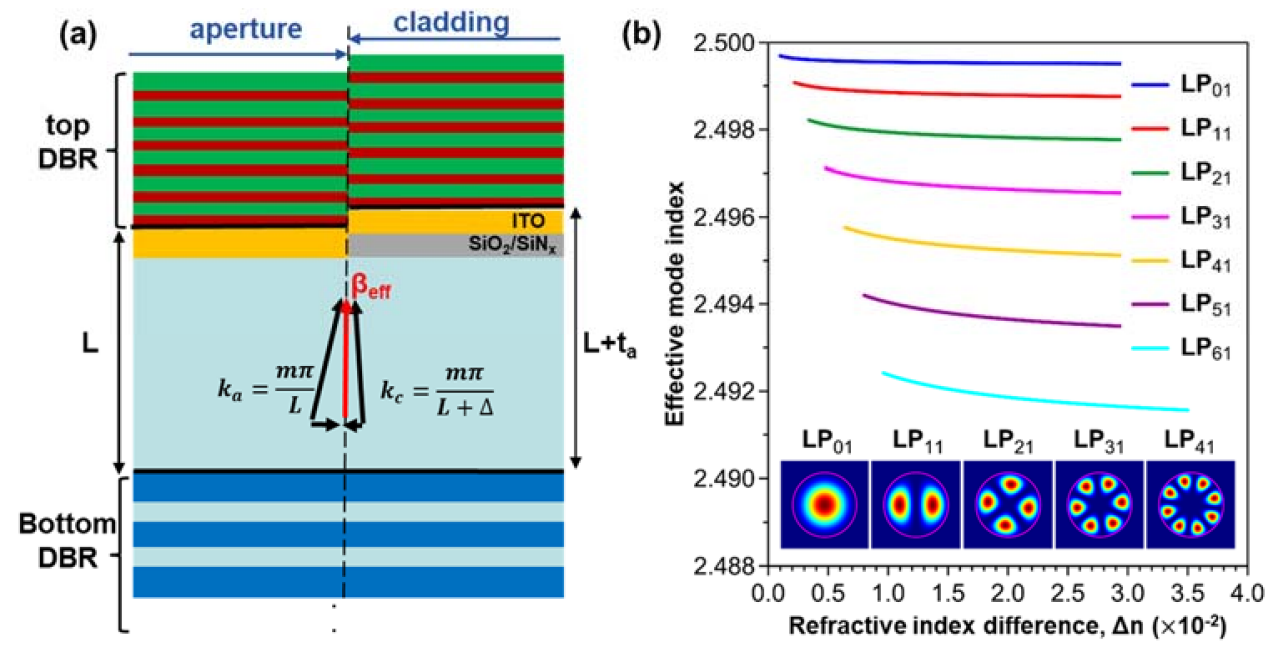

Figure 4. (a) Schematic illustration of anti-guiding effect due to the dielectric aperture (b) Calculated mode effective indices of $\mathrm{LP}_{\mathrm{mn}}$ modes of a 6- $\mu \mathrm{m}$-diameter nitride VCSEL with varying index difference $(\Delta \mathrm{n})$ between aperture and cladding region 2 . The carrier aperture dimension in $(\mathbf{b})$ follows the reference [24] (Data from [24]).

In this report, the progress of two different types of nitrides VCSELs will be reviewed in session II. Proven strategies in top mirror fabrication to overcome the anti-guiding effects will be discussed in session III.

\section{Category of III-Nitride VCSELs}

As aforementioned, III-nitride VCSELs are categorized into 2 types according to the combination of both end mirrors. The hybrid-type VCSEL possesses one mirror by epitaxial growth, and the other by dielectric deposition. The first demonstration is by T.C. Lu et al., and the schematic device structure is shown in Figure 5a,b. The device consisted of 29 pairs of AlN/GaN epitaxial DBR mirrors at n-side, $5 \lambda$-long GaN cavity 
with InGaN multiple-quantum-wells (MQW) at the anti-node, $\lambda / 8$-thick ITO at the node, and 8 pairs of $\mathrm{SiO}_{2} / \mathrm{Ta}_{2} \mathrm{O}_{5}$ dielectric mirrors at top. Although short-period AlN/GaN superlattices (SLs) were inserted after every 5 pairs of AlN/GaN DBR to alleviate the strain energy accumulation, strain-induced defects were still observed. Figure $5 \mathrm{c}$ showed a transmission electron microscopy (TEM) image of an AlN/GaN DBR. The high density of surface depression (a.k.a. pits) was observed on the top surface of AlN only, which is attributed to the high tensile strain of AlN on the GaN templates. The pits with a central screw dislocation are strong carrier leakage paths. Therefore, the first nitride VCSEL can only be operated under low temperature to retain a high carrier density in MQW.

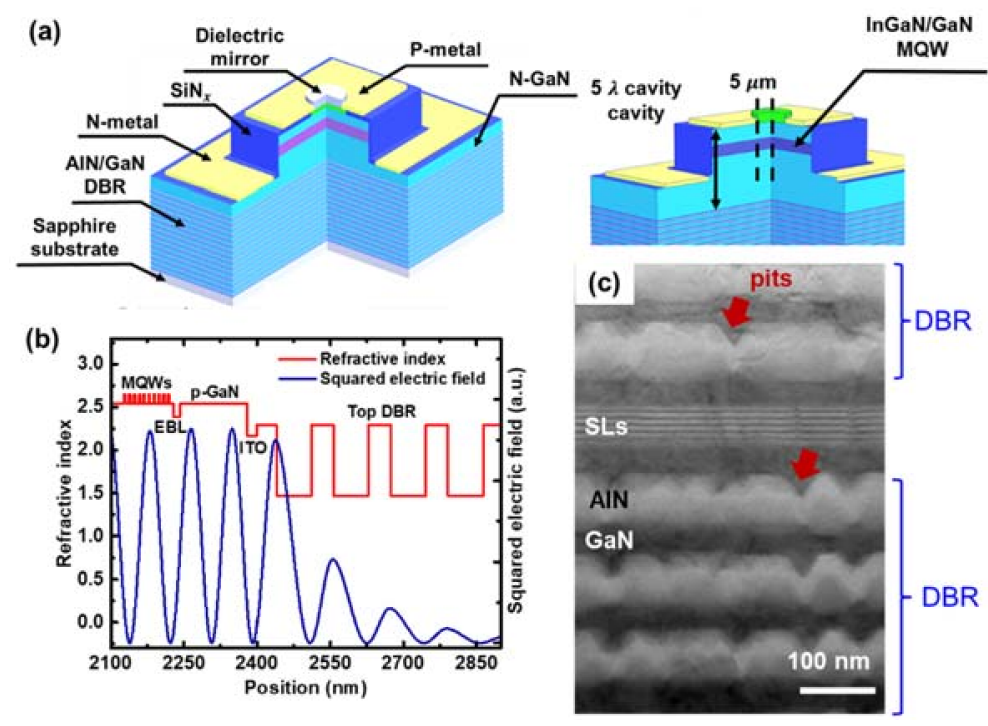

Figure 5. (a) Schematic structure and (b) optical mode intensity profile of first hybrid-type nitride VCSEL. (c) TEM observation of a defective area in AlN/GaN DBR. The epilayer structure for optical simulation of (b) followed the reference [12] (Data from [12]).

Therefore, the advancement of hybrid-type nitride DBR focused on circumventing the epitaxial strain. The most common approach is to replace the AlN with AlInN latticematched to GaN. According to Vegard's Law, the Al\% of lattice-matched AlInN is around $82 \%$. However, the AlInN epitaxial growth is critical because the ideal growth conditions of AlN and InN are way apart, and its strain status is sensitive to the composition variation. Gas-phase reaction, surface pits, and phase separation were all reported for a single AlInN layer growth on GaN [64-67]. Besides, the optimal growth temperature of AlInN $\left(\mathrm{T}_{\mathrm{g}}=850 \sim 900{ }^{\circ} \mathrm{C}\right)$ also differed much from that of $\mathrm{GaN}\left(\mathrm{T}_{\mathrm{g}}=1050 \sim 1100{ }^{\circ} \mathrm{C}\right)$. Therefore, improper treatment at AlInN/GaN growth interface could cause either In desorption or In segregation at the interface [68-70]. High reflectivity lattice-matched AlInN/GaN DBR was demonstrated early in 2003 as in ref. [71], but full VCSELs with lattice-matched AlInN/GaN DBR were not demonstrated until 2012. The schematic structure of the first nitride VCSEL with AlInN/GaN bottom DBR is shown in Figure 6 [21]. The large time gap between DBR and VCSEL demonstration might also be attributed to the significant challenges in the epitaxial growth integration. To date, the single VCSEL with the highest $P_{\max }(>10 \mathrm{~mW})$ utilized lattice-matched AlInN/GaN DBR. If the challenges in growth can be properly dealt with, nitride VCSEL array with epitaxial DBR is promising for high-power application [42]. 


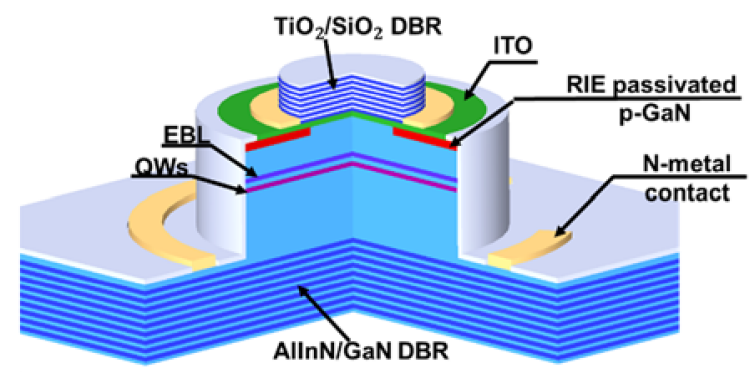

Figure 6. Schematic structure of first hybrid-type VCSEL with AlInN/GaN DBR.

Another strategy to fabricate strain-free epitaxial DBRs is by forming nanoporous GaN via electrochemical (EC) etching. Unintentionally doped GaN (UID-GaN) and heavily doped $n-G a N\left(n^{+}-\mathrm{GaN}\right)$ layers were grown alternatively with designed thicknesses, followed by common VCSEL device epi as described in Figure 5. The epi layer is etched to expose the sidewall of UID $/ \mathrm{n}^{+}-\mathrm{GaN}$ layers, then the substrate is positively biased in the buffered HF solution for EC etching [72]. Because of the different conductivity between UID-GaN and $n^{+}-\mathrm{GaN}$, it's possible to only porosity the $\mathrm{n}^{+}-\mathrm{GaN}$ layers with deliberately chosen bias voltage and HF concentration. The index contrast between un-etched $\mathrm{u}-\mathrm{GaN}$ and porous $\mathrm{n}^{+}-\mathrm{GaN}$ can be up to $0.5 \sim 0.8$, which is in the same level of dielectric DBR's in Table 2. As a result, the required total thickness is also narrower than the epitaxial DBR's. Nano-porous III-nitride DBR was firstly demonstrated by J. Han et al. [73]. Optically pumped lasing of nitride VCSELs were demonstrated in 2015, and the electrically pumped lasing is demonstrated by Masabih et al. in 2019 [51,74,75]. The most significant advantage of nano-porous DBR is the ease of growth. Common $n-G a N$ growth conditions in blue LEDs can be directly applied. However, integrating such DBR into real devices could still be challenging since the above device epi must not be EC-etched. The passivation layer must sustain a 10 -volt reverse-bias stress in HF solution. Another challenge for the nano-porous DBR is the low thermal conductivity with air voids, which might inherently limit the $\mathrm{P}_{\max }$ performance.

Dual-type VCSELs possess deposited dielectric DBRs from both sides. The major challenge lies in the exposure of the bottom surface with a thickness precision. The first dualtype III-nitride DBR was demonstrated by Nichia Corp., and the schematic process route is illustrated in Figure 7 [11]. VCSEL epi was grown on sapphire or GaN and transferred to a sub-carrier via die-bonding and laser lift-off (LLO) or chemical-mechanical polishing $(\mathrm{CMP})$ processes. To reduce the epi thickness to the target cavity length, the transferred epi was thinned via CMP. The process was critical for multiple reasons: (1) conventional LLO process is not applicable to GaN homoepitaxy. The GaN heteroepitaxy on sapphire has its limit in crystal quality. (2) Lack of feedback design to stop the CMP process. As the tolerance of cavity length error becomes narrow for short cavity lasers, residual thickness control will be extremely challenging. (3) The CMP still damages the epilayer near the surface. Restoring the electric contact characteristic requires other engineering efforts.
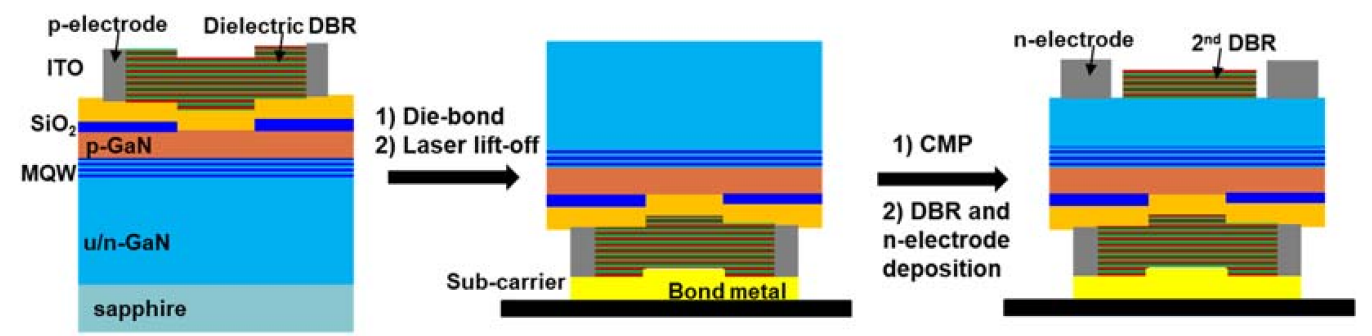

Figure 7. Schematic fabrication process of firstly demonstrated dual-type nitride VCSEL.

In 2015, Izumi et al. demonstrated dual-type DBR by epitaxial lateral overgrowth (ELOG) on pre-deposited dielectric DBRs as depicted in Figure 8 [35]. A 14.5-pair $\mathrm{SiO}_{2} / \mathrm{SiN}_{\mathrm{X}}$ 
DBR was deposited and patterned on the high-quality n-GaN substrate, and the n-contact was directly formed on the substrate backside. The rest of the device design and fabrication process on the top side is similar. Although the film coalescence and thickness control on the ELOG n-GaN could still be challenging, the crystal quality and the backside contact characteristics were significantly improved. Figure 9 demonstrated another potential route for defining the cavity length with photoelectricalchemical (PEC) etching [76-78]. Prior to the device epitaxy, an InGaN sacrificial layer with a near-UV bandgap $(\lambda=385 \mathrm{~nm} \sim 405$ $\mathrm{nm}$ ) was grown on a bulk GaN substrate. After a similar VCSEL process was done from the top side, another deep-etch was performed to expose the sidewall of the sacrificial layer. The wafer was then bonded to another sub-carrier. Under near-UV illumination, only the sacrificial layer dissolves in $\mathrm{KOH}$ solution. After the sacrificial layer was completely etched, devices were transferred to the sub-carrier with a well-defined cavity length and were ready for the processes at the backside. Electrically pumped PEC-transferred III-nitride VCSEL was first demonstrated by C. Holder et al. and was continuously improved in the same affiliation [44-50]. In comparison with the ELOG-DBR stack with a micrometer in height and $\sim 10$ micrometer in width, cavity length control with a planar sacrificial layer is much less critical. However, the PEC etching rate could be still limited by the carrier and materials transport after the undercut goes deep; passivation of the device epi is also essential for the yield.

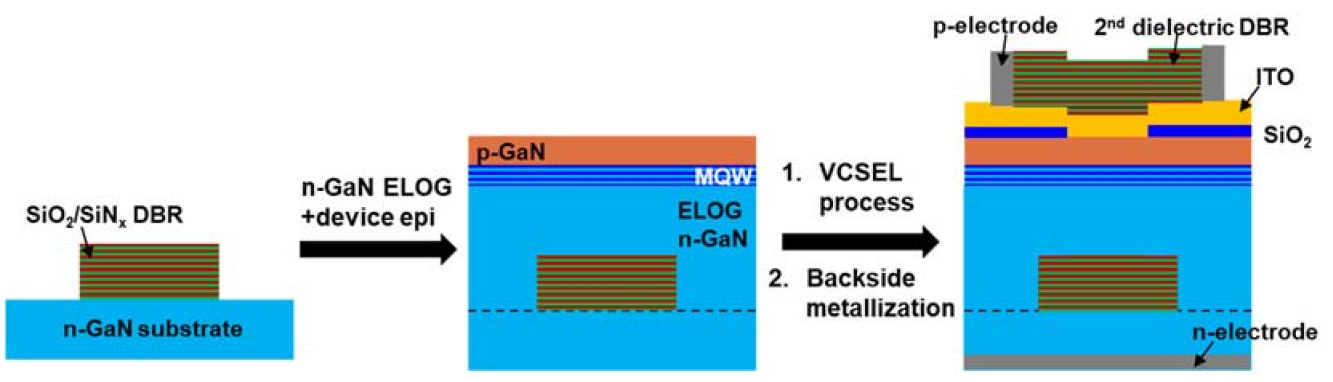

Figure 8. Schematic process route of dual-type VCSEL with ELOG bottom mirror.

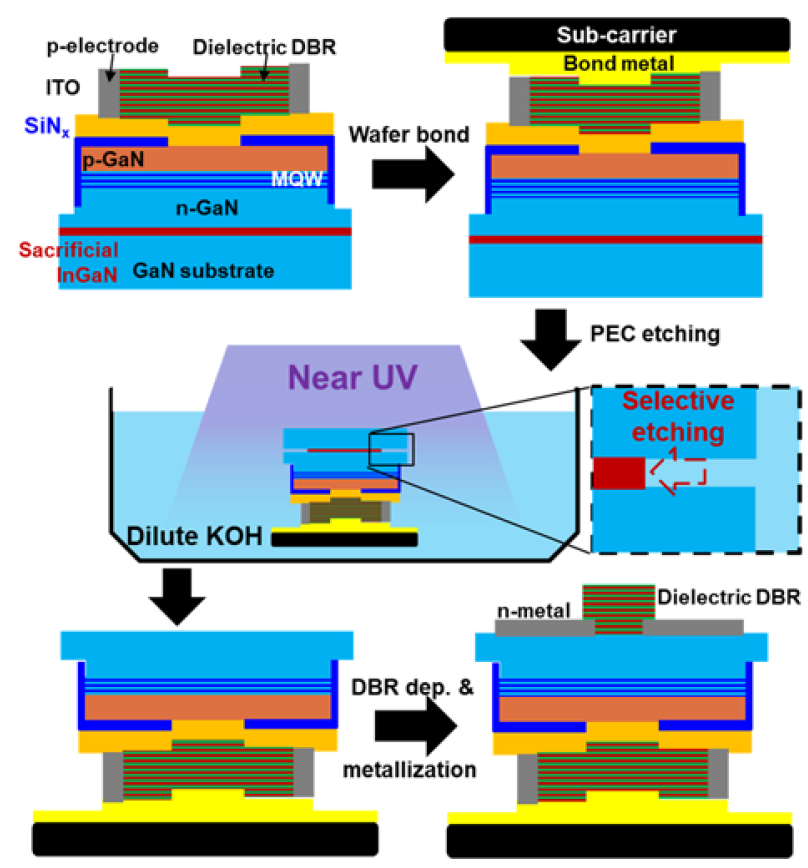

Figure 9. Schematic process of dual-type VCSEL via PEC-etching.

In 2018, T. Hamaguchi et al. demonstrated a curved DBR mirror at the backside substrate to form a stable cavity with a long cavity length $(>50 \mu \mathrm{m})$. [37,38] The lens 
was originally formed by re-flowing the resin plates on the substrate backside, and the shape was transferred to GaN via dry etching. The curved mirror focuses the propagating Gaussian beam back to the active region. Therefore, the diffraction loss in a long cavity could be minimized. Although the presented $\mathrm{P}_{\max }$ still has room for improvement, the latest $\mathrm{J}_{\mathrm{th}}$ was reported as low as $4 \mathrm{kA} / \mathrm{cm}^{2}$. Besides, a long cavity has a strong potential for mass production. For example, the much narrower mode spacing makes the cavity length tolerance irrelevant; a thick base is also beneficial for thermal management and is more robust for packaging.

\section{Novel Carrier Aperture Designs}

To overcome the anti-guiding effects due to the deposited dielectric aperture, the optical path difference between the central region and cladding region needs to be compensated. An intuitive approach is to get rid of the dielectric mirror by passivating the cladding region by ion-implantation or plasma treatment. The schematic aperture design was shown in Figure 10a [37,38,43,45,49-51]. As a result, the vertical optical path between mirrors in both regions is identical. One could also enhance the optical path in the central region with an additional spacer as depicted in Figure 11b [79], or etch some p-GaN off in the cladding region as shown in Figure 10c,d [39-43]. If the optical path in the central region becomes longer than that of the cladding region instead, the lateral optical confinement alters from anti-guiding to guiding. Figure 10c,d both etched some p-GaN off, but (c) still adopted a dielectric layer to block the current (buried aperture) while (d) directly exploited the plasma-damaged surface as the carrier aperture. From the perspective mirror curvature, the original dielectric aperture yielded a concave-like mirror, aperture in Figure 10a yielded a planar mirror, and designs in Figure $10 \mathrm{~b}-\mathrm{d}$ yielded convex-like top mirrors.

(a)

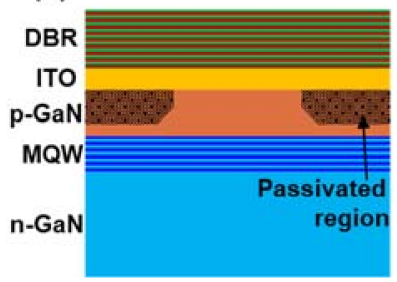

(b)

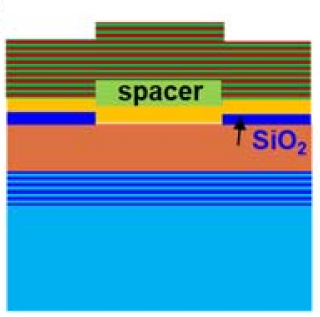

(c)

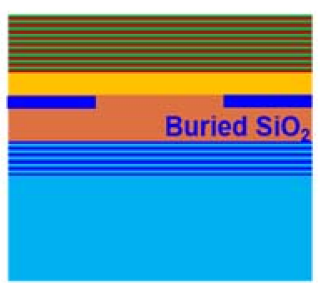

(d)

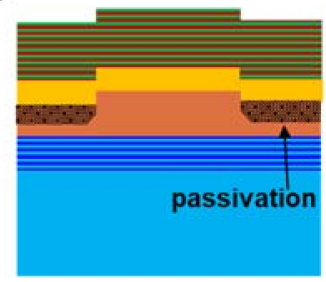

Figure 10. Schematic aperture designs with (a) ion-implantation or plasma passivation (b) additional spacer (c) buried $\mathrm{SiO}_{2}$ and (d) plasma etched and passivated cladding region for lateral optical confinement.

(a)

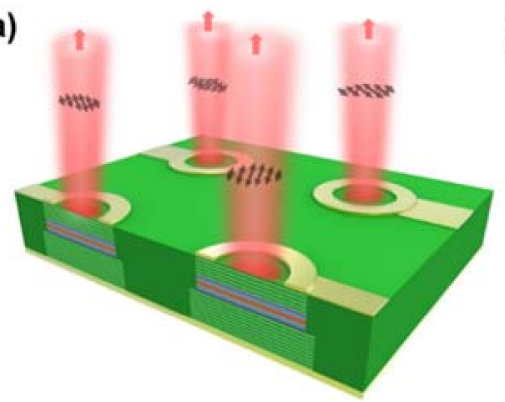

(b)

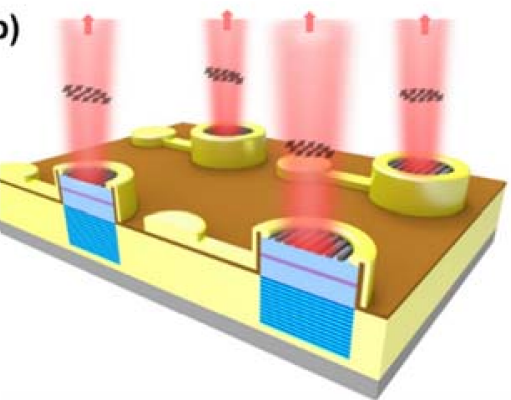

Figure 11. (a) Lasing with random polarization in conventional VCSEL arrays (b) lasing with pre-designed polarization by high-contrast grating (HCG) mirror.

With novel apertures in Figure $10 \mathrm{c}, \mathrm{d}$, the maximum output power is greatly enhanced. Single VCSEL demonstrated $P_{\max }>5 \mathrm{~mW}$ performance and $16 \times 16$ VCSEL array reached $P_{\max }>1 \mathrm{~W}$ [42] The maximum output power of III-nitride VCSELs is no longer less than the arsenide and phosphide-based VCSELs. The side effect of novel aperture design is the loss of discrimination to higher-order modes [24]. As shown in Figure $4 \mathrm{~b}$ as the effective refractive index difference $(\Delta \mathrm{n})$ between the central region and cladding region becomes 
positive, optical modes with higher azimuthal order are allowed. Fortunately, multi-mode lasing is not a critical issue for most blue VCSEL applications.

\section{Polarization Control of III-Nitride VCSEL}

Forming a VCSEL array is the most cost-effective way to push the $P_{\max }$ up to another order. Unlike the TE-mode lasing is strongly preferred in EELs, the polarization in the VCSEL array on the basal plane is random as shown in Figure 11a. If the applications require lasing in specific polarization, for example, holographic projection and polarizationmultiplexing in visible communication, the final device output power will be reduced in half after including an external linear polarizer. Therefore, polarization control is also an interesting topic for VCSEL applications. Although manipulating the polarization to an arbitrary angle is difficult, it is possible to restrict polarization in the VCSEL array in the same direction as depicted in Figure 11b.

The randomness of polarization originates from the circularly invariant gain and loss in the VCSEL structure. To discriminate one polarization mode from the other, we must differentiate their optical gain or losses. For example, growing the VCSEL structure in nonpolar and semipolar planes, or replacing the DBR with high contact grating (HCG) were proven effective in reducing the circular symmetry without changing the shape of the aperture.

Growing devices on nonpolar planes or semipolar planes mitigate QCSE. Saturated optical gain is also enhanced due to the improved wavefunction overlap and transition matrix elements. [80,81] However, the origin of polarization discrimination comes from the anisotropic strain along the a-axis and c-axis. Because the c/a ratio within AlN, GaN, and $\mathrm{InN}$ are all different, $\mathrm{AlGaN}$ (or $\mathrm{InGaN}$ ) on the $\mathrm{GaN}$ template will experience a different amount of strain along with the a-axis and c-axis projection. The strain of AlN and InN on $\mathrm{GaN}$ within the basal plane $\left(\varepsilon_{\mathrm{x}}\right)$ and along the c-axis $\left(\varepsilon_{\mathrm{z}}\right)$ were also summarized in Table 1. Figure 12a depicted the nomenclature of orientations in the non-polar and semipolar epitaxy system. $z^{\prime}$ is the growth normal direction, $y^{\prime}$ is parallel to the intersection of the growth plane and (0001) basal plane, and $x^{\prime}$ is parallel to the c-axis projection on the growth plane. For example, the $x^{\prime}, y^{\prime}$, and $z^{\prime}$ direction of the nonpolar (10-10) plane is [0001], [11-20], and [10-10], respectively. For the semipolar (20-2-1) plane, the $x^{\prime}, y^{\prime}$, and $z^{\prime}$ direction is [10-14], [1-210], and [20-2-1], respectively. Theoretical band structure calculation predicted the top four valence sub-bands are more $y^{\prime}$-polarized, only the bottom two sub-bands are more $\mathrm{x}^{\prime}$-polarized [82]. Non-polar and semipolar LED studies also verified that the spontaneous emission is $y^{\prime}$-polarized, and the degree of polarization (DOP) is enhanced with a higher indium content in the active region [83-85]. Therefore, the optical gain of $y^{\prime}$-polarized light will also be much higher than the $x^{\prime}$-polarized light due to the prevailing transition matrix element and population inversion factor, $\mathrm{f}_{\mathrm{c}}-\mathrm{f}_{\mathrm{v}}$. Blue and violet VCSEL on (10-10) and (20-2-1) planes demonstrated a 100\% DOP after lasing, and their polarization was all along the [1-210] direction [45-49]. Figure 12b schematically illustrated the polarization intensity profile of nonpolar and semipolar III-nitride VCSELs.

(a)

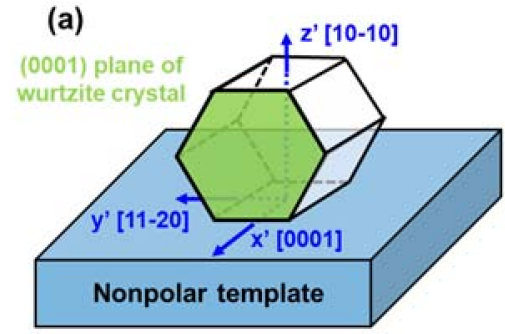

(b)

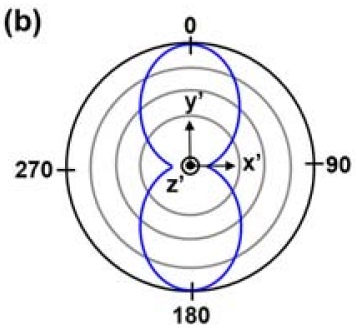

Figure 12. (a) Illustration of $x^{\prime}, y^{\prime}$ and $z^{\prime}$ orientation in non-polar epitaxy system as an example. (b) Schematic illustration of polarization of non-polar VCSELs when I $>\mathrm{I}_{\mathrm{th}}$.

High contrast grating (HCG) mirror was firstly demonstrated in arsenide-based VCSELs in the form of the suspending GaAs bars [86]. The reflectivity and the stop-band 
will be higher and broader if the refractive index difference between grating materials and cladding materials (mostly air) is high. If the periodicity of the grating $(\Lambda)$ is in the sub-wavelength region, the parallel bars could be regarded as optically coupled slab waveguides with a common mode propagation constant $\beta$. Under a specific combination of the grating thickness $(\mathrm{h})$ and bar width $(\mathrm{w})$, the boundary conditions might yield a pure imaginary $\beta$, or the imaginary part of $\beta$ is much higher than its real part [87-89]. Under such a combination of grating parameters, the incident wave could not (or barely could) propagate in the HCG region, resulting in a high reflectance of the incident wave.

Since suspending GaN bars in the sub-wavelength scale might be quite difficult to fabricate, a patterned high index dielectric could be a practical alternative. Chang et.al demonstrated optically pumped and electrically pumped III-nitride VCSEL with a subwavelength $\mathrm{TiO}_{2}$ grating replacing conventional dielectric DBRs [90,91]. The lasing modes are either parallel (TE-mode) or perpendicular (TM-mode) to the $\mathrm{TiO}_{2}$ bars as depicted in Figure 13a. Figure 13b-d are calculated reflection spectrum and reflectivity mapping with different grating parameters. $\mathrm{F}_{\mathrm{W}}$ and $\mathrm{F}_{\mathrm{h}}$ are normalized grating parameters defined by:

$$
\begin{aligned}
& F_{w}=\frac{w}{\Lambda} \\
& F_{h}=\frac{h}{\Lambda}
\end{aligned}
$$
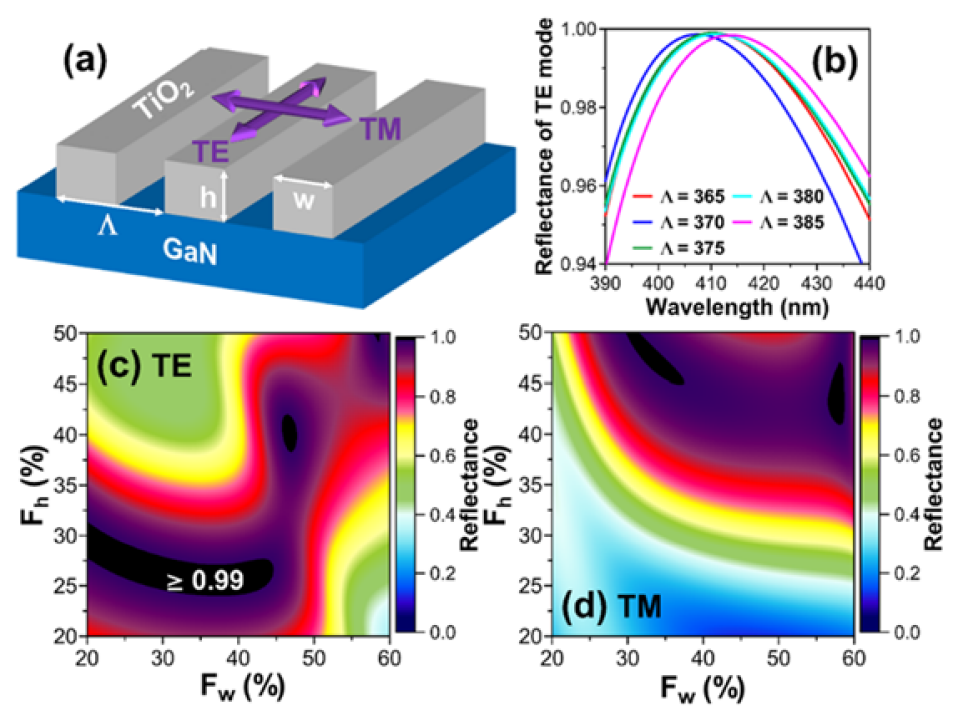

Figure 13. (a) Schematic illustration of TE-mode and TM-mode polarization in $\mathrm{TiO}_{2} \mathrm{HCG}$ on GaN (b) Reflectance spectrum of selected HCG structures. Reflectance mapping in the $\mathrm{F}_{\mathrm{W}} / \mathrm{F}_{\mathrm{h}}$ parameter space with (c) TE-mode and (d) TM-mode polarization.

The selected grating structures with $\Lambda$ from $365 \mathrm{~nm}$ to $385 \mathrm{~nm}$ in Figure $13 \mathrm{~b}$ were summarized in Table 4 . With a proper design, $\mathrm{R}>99 \%$ with $\sim 20 \mathrm{~nm}$ bandwidth could be achieved. Figure $13 \mathrm{c}$,d plotted the reflectivity mapping with varying $\mathrm{F}_{\mathrm{w}}$ and $\mathrm{F}_{\mathrm{h}}$ under $\Lambda=375 \mathrm{~nm}$ and $\lambda=410 \mathrm{~nm}$. Because the boundary conditions between TE-mode and TM-mode are different, the parameter design space for high reflectance also differs. If the combination of $\left(\mathrm{F}_{\mathrm{W}}, \mathrm{F}_{\mathrm{h}}\right)$ only gives a high $\mathrm{R}$ to one polarization mode, the other polarization will be discriminated for lasing. For example, if $\left(F_{w}, F_{h}\right)$ in Figure $13 c, d$ is $(30 \%, 28 \%), R$ for TE-mode exceeds $99 \%$ while $\mathrm{R}$ for TM-mode is less than $40 \%$. As a result, TE-mode lasing prevails. 
Table 4. The grating parameters of Figure $13 \mathrm{~b}$.

\begin{tabular}{ccc}
\hline $\boldsymbol{\Lambda} \mathbf{( n m )}$ & $\mathbf{F}_{\mathbf{w}}(\mathbf{\%})$ & $\mathbf{F}_{\mathbf{h}}(\mathbf{\%})$ \\
\hline 365 & 18.0 & 31.5 \\
370 & 21.0 & 29.5 \\
375 & 29.0 & 26.5 \\
380 & 31.5 & 25.5 \\
385 & 34.5 & 25.0 \\
\hline
\end{tabular}

\section{Outlook of III-Nitride VCSEL Research}

After a decade of solid development, blue III-nitride VCSELs have achieved remarkable progress in fabrication technologies and device performances. New applications with III-nitride VCSELs such as VR/AR displays and micro-projectors are also on the way to market. In near future, the frontier of III-nitride VCSEL research will keep advancing in various dimension; for example, higher power density, broader applicable spectral region, or much lower threshold pumping level.

To further enhance the output power density, one might consider stacking multiple VCSEL device epilayers with tunnel junctions. Tunnel junction has been applied to single III-nitride EELs to circumvent the relatively poor current spreading and contact resistances of p-GaN [92]. A similar concept was also demonstrated with single III-nitride VCSEL [93]. Combining the vertical device epi stack and lateral array structure, the absolute output power from a monolithic VCSEL array chip has the potential to exceed the output power of EELs.

III-nitride materials also have the potential for fabricating VCSELs in a spectral region other than blue. The bottleneck for III-nitride VCSELs working in longer wavelengths is in growing high In-content QWs. The strong compressive strain in QW might trigger catastrophic materials degradation such as phase separation or macroscopic voids [94-97]. Since nitride-based aquamarine to red EELs and green VCSELs have been demonstrated, there shall be no real technology bottleneck in the current stage [98-100]. However, since the index contrast between AlInN and GaN is weaker and the Bragg's wavelength is longer, the epitaxial DBR growth will be more critical as well. Fulfillment of R-G-B VCSEL triggers new design possibilities in VR/AR headset/glasses or compact-sized holographic projectors. In other directions, III-nitride is also the most promising candidate in fabricating ultra-violet (UV) VCSELs. The challenge in growth becomes the strain and morphology management with Al-rich AlGaN. Similarly, since electrically pumped nitride EELs have been demonstrated from $270 \mathrm{~nm}$ to $405 \mathrm{~nm}$, [101,102] growth of high-quality AlGaN active region shall not be the limiting bottleneck either [103-106]. However, the DBR technology for the UV spectral region needs further development. Many high-index dielectrics such as $\mathrm{TiO}_{2}$ are strongly absorbing under UV light, and GaN cannot be used in UVB/UVC epitaxial DBR due to the band edge absorption. Therefore, the cavity design and fabrication of UV VCSELs will be even more critical than that of long-wavelength VCSELs. UV VCSELs can be used as an alternative component in an atomic clock, UV resin-curing, gas sensing, and disinfections [107-109].

To further reduce the threshold pumping level, the lateral optical confinement requires a more progressive design; for example, optically coupled monolithic nano-rod arrays $[110,111]$. Because crystallographic facets naturally form during the regrowth of III-nitride nanowires, DBRs are not necessary for a high-Q cavity. Optically pumped and electrically pumped lasing of coupled III-nitride nano-rod array have been demonstrated with a low pumping density [112-114]. Since the photons were strongly confined in the lateral direction, photons after lasing still emit along the surface normal. Another approach is to fabricate exciton-polariton lasers for the ultra-low threshold pumping density. Although the structure of the exciton-polariton laser resembles the VCSEL structure, the fundamental physical mechanism is totally different. Exciton-polariton lasing originates from the strong coupling between cavity photon and bounded exciton. The bosonic nature allows excitons in the cavity to condensate in the same energy level, and the phase is 
equalized by the standing photon waves [115]. Therefore, its theoretical pumping level could be ordered lower than that of photonic lasers because population inversion is not required. Electrically pumped polariton laser has been demonstrated in GaAs-based materials, [116,117] exciton-polariton coupling was also observed under optical pumping in the nitride system [118-120]. Because the binding energy of exciton in GaAs is low $(\sim 5 \mathrm{meV})$, polariton-exciton lasing under room temperature is highly unlikely. AlGaN materials possess a high exciton binding energy from $25 \mathrm{meV}$ to $60 \mathrm{meV}$, which is very promising for an exciton-polariton laser operating above room temperature [121]. The realization of room-temperature exciton-polariton laser provides a platform for studying the multiple-body effects in a bosonic system, which might be essential for the development of quantum information technologies.

In conclusion, III-nitride VCSELs have encountered many challenges and opportunities due to their unique materials properties. High-power blue VCSELs have been demonstrated after breakthroughs in mirror and aperture fabrication technology. The authors believe the scope and functionality of III-nitride VCSELs and their derivatives will keep expanding in all dimensions in the upcoming future.

Author Contributions: Original draft writing and editing, C.-Y.H.; simulation, K.-B.H.; literature survey, Z.-T.H. and W.-H.H. (Wen-Hsuan Hsieh); data curation, W.-H.H. (Wei-Hao Huang); conceptualization and supervision, T.-C.L. All authors have read and agreed to the published version of the manuscript.

Funding: This work has been supported in part by the Ministry of Science and Technology in TAIWAN under Contract No. MOST 109-2221-E-009-150, and MOST 109-2124-M-009-005.

Institutional Review Board Statement: Not applicable.

Informed Consent Statement: Not applicable.

Data Availability Statement: Not applicable.

Acknowledgments: The authors would like to especially thank Shing-Chung Wang of NCTU for his guidance and pioneering work in GaN-based VCSELs. The authors would like to acknowledge Nano Facility Center (NFC), Center for Nano Science and Technology (CNST) in NYCU, and also the Industrial Technology Research Institute (ITRI) for their technical support.

Conflicts of Interest: The authors declare no conflict of interest.

\section{References}

1. Nakamura, S.; Pearton, S.; Fasol, G. The Blue Laser Diode; Springer: Berlin/Heidelberg, Germany, 2000; ISBN 978-3-642-08579-6.

2. Nakamura, S.; Senoh, M.; Nagahama, S.; Iwasa, N.; Yamada, T.; Matsushita, T.; Kiyoku, H.; Kiyoku, H.; Sugimoto, Y.S.Y. InGaN-Based Multi-Quantum-Well-Structure Laser Diodes. J. Jpn. Appl. Phys. 1996, 35, L74. [CrossRef]

3. Nakamura, S.; Senoh, M.; Nagahama, S.-I.; Iwasa, N.; Yamada, T.; Matsushita, T.; Kiyoku, H.; Sugimoto, Y.; Kozaki, T.; Umemoto, H.; et al. InGaN/GaN/AlGaN-based laser diodes with modulation-doped strained-layer superlattices grown on an epitaxially laterally overgrown GaN substrate. Appl. Phys. Lett. 1998, 72, 211-213. [CrossRef]

4. Naniwae, K.; Itoh, S.; Amano, H.; Itoh, K.; Hiramatsu, K.; Akasaki, I. Growth of single crystal GaN substrate using hydride vapor phase epitaxy. J. Cryst. Growth 1990, 99, 381-384. [CrossRef]

5. Motoki, K.; Okahisa, T.; Matsumoto, N.; Matsushima, M.; Kimura, H.; Kasia, H.; Takemoto, K.; Uematsu, K.; Hirano, T.; Nakayama, M.; et al. Preparation of Large Freestanding GaN Substrates by Hydride Vapor Phase Epitaxy Using GaAs as a Starting Substrate. Appl. Phys. 2001, 40, L140. [CrossRef]

6. Golan, Y.; Wu, X.H.; Speckb, J.S.; Vaudoc, R.P.; Phanse, V.M. Morphology and microstructural evolution in the early stages of hydride vapor phase epitaxy of GaN on sapphire. Appl. Phys. Lett. 1998, 73, 3090. [CrossRef]

7. Tavernier, P.R.; Etzkorn, E.V.; Wang, Y.; Clarke, D. Two-step growth of high-quality GaN by hydride vapor-phase epitaxy. Appl. Phys. Lett. 2000, 77, 1804. [CrossRef]

8. Kamikawa, T.; Kawaguchi, Y.; Vaccaro, P.O.; Ito, S.; Kawanishi, H. Highly reliable $500 \mathrm{~mW}$ laser diodes with epitaxially grown AlON coating for high-density optical storage. Appl. Phys. Lett. 2009, 95, 031106. [CrossRef]

9. König, H.; Lell, A.; Ali, M.; Stojetz, B.; Eichler, C.; Peter, M.; Löffler, A.; Strauss, U.; Baumann, M.; Balck, A.; et al. Blue $450 \mathrm{~nm}$ high power semiconductor continuous wave laser bars exceeding rollover output power of 80 W. High. Power Diode Laser Technol. XVI 2018, 10514, 1051402. [CrossRef] 
10. Murayama, M.; Nakayama, Y.; Yamazaki, K.; Hoshina, Y.; Watanabe, H.; Fuutagawa, N.; Kawanishi, H.; Uemura, T.; Narui, H. Watt-Class Green (530 nm) and Blue (465 nm) Laser Diodes. Phys. Status Solidi (A) 2017, 215, 1700513. [CrossRef]

11. Higuchi, Y.; Omae, K.; Matsumura, H.; Mukai, T. Room-Temperature CW Lasing of a GaN-Based Vertical-Cavity Surface-Emitting Laser by Current Injection. Appl. Phys. Express 2008, 1, 121102. [CrossRef]

12. Lu, T.-C.; Kao, C.-C.; Kuo, H.-C.; Huang, G.-S.; Wang, S.-C. CW lasing of current injection blue GaN-based vertical cavity surface emitting laser. Appl. Phys. Lett. 2008, 92, 141102. [CrossRef]

13. Strite, S. GaN, AlN, and InN: A review. J. Vac. Sci. Technol. B Microelectron. Nanometer Struct. 1992, 10, 1237-1266. [CrossRef]

14. Ambacher, O.; Dimitrov, R.; Stutzmann, M.; Foutz, B.E.; Murphy, M.J.; Smart, J.A.; Shealy, J.R.; Weimann, N.G.; Chu, K.; Chumbes, M.; et al. Role of Spontaneous and Piezoelectric Polarization Induced Effects in Group-III Nitride Based Heterostructures and Devices. Phys. Status Solidi 1999, 216, 381. [CrossRef]

15. Bernardini, F.; Fiorentini, V.; Vanderbilt, D. Spontaneous polarization and piezoelectric constants of III-V nitrides. Phys. Rev. B 1997, 56, R10024-R10027. [CrossRef]

16. Polian, A.; Grimsditch, M.; Grzegory, I. Elastic constants of gallium nitride. J. Appl. Phys. 1996, 79, 3343-3344. [CrossRef]

17. Wright, A.F. Elastic properties of zinc-blende and wurtzite AlN, GaN, and InN. J. Appl. Phys. 1997, 82, 2833-2839. [CrossRef]

18. Feezell, D.F.; Speck, J.S.; DenBaars, S.P.; Nakamura, S. Semipolar 20-2-1 InGaN/GaN Light-Emitting Diodes for High-Efficiency Solid-State Lighting. J. Disp. Technol. 2013, 9, 190. [CrossRef]

19. Chuang, S.L. Optical gain of strained wurtzite GaN quantum-well lasers. IEEE J. Quantum Electron. 1996, 32, 1791-1800. [CrossRef]

20. Vehse, M.; Michler, P.; Lange, O.; Röwe, M.; Gutowski, J.; Bader, S.; Lugauer, H.-J.; Brüderl, G.; Weimar, A.; Lell, A.; et al. Optical gain and saturation in nitride-based laser structures. Appl. Phys. Lett. 2001, 79, 1763-1765. [CrossRef]

21. Cosendey, G.; Castiglia, A.; Rossbach, G.; Carlin, J.-F.; Grandjean, N. Blue monolithic AlInN-based vertical cavity surface emitting laser diode on free-standing GaN substrate. Appl. Phys. Lett. 2012, 101, 151113. [CrossRef]

22. Furuta, T.; Matsui, K.; Horikawa, K.; Ikeyama, K.; Kozuka, Y.; Yoshida, S.; Akagi, T.; Takeuchi, T.; Kamiyama, S.; Iwaya, M.; et al. Room-temperature CW operation of a nitride-based vertical-cavity surface-emitting laser using thick GaInN quantum wells. Jpn. J. Appl. Phys. 2016, 55, 05FJ11. [CrossRef]

23. Ikeyama, K.; Kozuka, Y.; Matsui, K.; Yoshida, S.; Akagi, T.; Akatsuka, Y.; Koide, N.; Takeuchi, T.; Kamiyama, S.; Iwaya, M.; et al. Room-temperature continuous-wave operation of GaN-based vertical-cavity surface-emitting lasers with n-type conducting AlInN/GaN distributed Bragg reflectors. Appl. Phys. Express 2016, 9, 102101. [CrossRef]

24. Hayashi, N.; Ogimoto, J.; Matsui, K.; Furuta, T.; Akagi, T.; Iwayama, S.; Takeuchi, T.; Kamiyama, S.; Iwaya, M.; Akasaki, I. A GaN-Based VCSEL with a Convex Structure for Optical Guiding. Phys. Status Solidi (A) 2018, 215, 1700648. [CrossRef]

25. Akagi, T.; Kozuka, Y.; Ikeyama, K.; Iwayama, S.; Kuramoto, M.; Saito, T.; Tanaka, T.; Takeuchi, T.; Kamiyama, S.; Iwaya, M.; et al. High-quality AlInN/GaN distributed Bragg reflectors grown by metalorganic vapor phase epitaxy. Appl. Phys. Express 2020, 13, 125504. [CrossRef]

26. Matsui, K.; Kozuka, Y.; Ikeyama, K.; Horikawa, K.; Furuta, T.; Akagi, T.; Takeuchi, T.; Kamiyama, S.; Iwaya, M.; Akasaki, I. GaN-based vertical cavity surface emitting lasers with periodic gain structures. Jpn. J. Appl. Phys. 2016, 55, 05FJ08. [CrossRef]

27. Bi, W.; Kuo, H.-C.; Ku, P.-C.; Shen, B. Handbook of GaN Semiconductor Materials and Devices; CRC Press: Boca Raton, FL, USA, 2017. [CrossRef]

28. Hsieh, D.H.; Tzou, A.J.; Kao, T.S.; Lai, F.I.; Lin, D.W.; Lin, B.C.; Lu, T.C.; Lai, W.C.; Chen, C.H.; Kuo, H.C. Improved carrier injection in GaN-based VCSEL via AlGaN/GaN multiple quantum barrier electron blocking layer. Opt. Express 2015, 23, 27145-27151. [CrossRef] [PubMed]

29. Chang, T.-C.; Kuo, S.-Y.; Lian, J.-T.; Hong, K.-B.; Wang, S.-C.; Lu, T.-C. High-temperature operation of GaN-based vertical-cavity surface-emitting lasers. Appl. Phys. Express 2017, 10, 112101. [CrossRef]

30. Chang, T.-C.; Hashemi, E.; Hong, K.-B.; Bengtsson, J.; Gustavsson, J.; Haglund, A.; Lu, T.-C. Electrically Injected GaN-Based Vertical-Cavity Surface-Emitting Lasers with TiO2 High-Index-Contrast Grating Reflectors. ACS Photon. 2020, 7, 861-866. [CrossRef]

31. Chang, T.-C.; Kuo, S.-Y.; Lian, J.-T.; Hong, K.-B.; Lu, T.-C.; Wang, S.-C. GaN-based vertical-cavity surface-emitting lasers operating at high temperature. In Proceedings of the 2017 22nd Microoptics Conference (MOC), Tokyo, Japan, 19-22 November 2017.

32. Omae, K.; Higuchi, Y.; Nakagawa, K.; Matsumura, H.; Mukai, T. Improvement in Lasing Characteristics of GaN-based VerticalCavity Surface-Emitting Lasers Fabricated Using a GaN Substrate. Appl. Phys. Express 2009, 2, 052101. [CrossRef]

33. Kasahara, D.; Morita, D.; Kosugi, T.; Nakagawa, K.; Kawamata, J.; Higuchi, Y.; Matsumura, H.; Mukai, T. Demonstration of Blue and Green GaN-Based Vertical-Cavity Surface-Emitting Lasers by Current Injection at Room Temperature. Appl. Phys. Express 2011, 4, 072103. [CrossRef]

34. Onishi, T.; Imafuji, O.; Nagamatsu, K.; Kawaguchi, M.; Yamanaka, K.; Takigawa, S. Continuous Wave Operation of GaN Vertical Cavity Surface Emitting Lasers at Room Temperature. IEEE J. Quantum Electron. 2012, 48, 1107-1112. [CrossRef]

35. Izumi, S.; Fuutagawa, N.; Hamaguchi, T.; Murayama, M.; Kuramoto, M.; Narui, H. Room-temperature continuous-wave operation of GaN-based vertical-cavity surface-emitting lasers fabricated using epitaxial lateral overgrowth. Appl. Phys. Express 2015, 8 , 062702. [CrossRef]

36. Hamaguchi, T.; Fuutagawa, N.; Izumi, S.; Murayama, M.; Narui, H. Milliwatt-class GaN-based blue vertical-cavity surfaceemitting lasers fabricated by epitaxial lateral overgrowth. Phys. Status Solidi (A) 2016, 213, 1170-1176. [CrossRef] 
37. Hamaguchi, T.; Tanaka, M.; Mitomo, J.; Nakajima, H.; Ito, M.; Ohara, M.; Kobayashi, N.; Fujii, K.; Watanabe, H.; Satou, S.; et al. Lateral optical confinement of GaN-based VCSEL using an atomically smooth monolithic curved mirror. Sci. Rep. 2018, 8, 10350. [CrossRef]

38. Hamaguchi, T.; Nakajima, H.; Fuutagawa, N. GaN-based Vertical-Cavity Surface-Emitting Lasers Incorporating Dielectric Distributed Bragg Reflectors. Appl. Sci. 2019, 9, 733. [CrossRef]

39. Kuramoto, M.; Kobayashi, S.; Akagi, T.; Tazawa, K.; Tanaka, K.; Saito, T.; Takeuchi, T. Enhancement of slope efficiency and output power in $\mathrm{GaN}$-based vertical-cavity surface-emitting lasers with a $\mathrm{SiO}_{2}$-buried lateral index guide. Appl. Phys. Lett. 2018, 112, 111104. [CrossRef]

40. Kuramoto, M.; Kobayashi, S.; Akagi, T.; Tazawa, K.; Tanaka, K.; Saito, T.; Takeuchi, T. High-output-power and high-temperature operation of blue GaN-based vertical-cavity surface-emitting laser. Appl. Phys. Express 2018, 11, 112101. [CrossRef]

41. Kuramoto, M.; Kobayashi, S.; Tazawa, K.; Tanaka, K.; Akagi, T.; Saito, T. In-phase supermode operation in GaN-based verticalcavity surface-emitting laser. Appl. Phys. Lett. 2019, 115, 041101. [CrossRef]

42. Kuramoto, M.; Kobayashi, S.; Akagi, T.; Tazawa, K.; Tanaka, K.; Nakata, K.; Saito, T. Watt-class blue vertical-cavity surface-emitting laser arrays. Appl. Phys. Express 2019, 12, 091004. [CrossRef]

43. Kuramoto, M.; Kobayashi, S.; Akagi, T.; Tazawa, K.; Tanaka, H.; Takeuchi, T. Nano-height cylindrical waveguide in GaN-based vertical-cavity surface-emitting lasers. Appl. Phys. Express 2020, 13, 082005. [CrossRef]

44. Holder, C.; Speck, J.S.; Denbaars, S.; Nakamura, S.; Feezell, D. Demonstration of Nonpolar GaN-Based Vertical-Cavity SurfaceEmitting Lasers. Appl. Phys. Express 2012, 5, 092104. [CrossRef]

45. Leonard, J.T.; Cohen, D.A.; Yonkee, B.P.; Farrell, R.M.; Margalith, T.; Lee, S.G.; DenBaars, S.P.; Speck, J.S.; Nakamura, S. Nonpolar III-nitride vertical-cavity surface-emitting lasers incorporating an ion implanted aperture. Appl. Phys. Lett. 2015, 107, 011102. [CrossRef]

46. Leonard, J.T.; Young, E.C.; Yonkee, B.P.; Cohen, D.A.; Margalith, T.; DenBaars, S.P.; Speck, J.S.; Nakamura, S. Demonstration of a III-nitride vertical-cavity surface-emitting laser with a III-nitride tunnel junction intracavity contact. Appl. Phys. Lett. 2015, 107, 091105. [CrossRef]

47. Holder, C.O.; Leonard, J.T.; Farrell, R.M.; Cohen, D.A.; Yonkee, B.; Speck, J.S.; Denbaars, S.; Nakamura, S.; Feezell, D.F. Nonpolar III-nitride vertical-cavity surface emitting lasers with a polarization ratio of $100 \%$ fabricated using photoelectrochemical etching. Appl. Phys. Lett. 2014, 105, 031111. [CrossRef]

48. Leonard, J.T.; Yonkee, B.P.; Cohen, D.A.; Megalini, L.; Lee, S.G.; Speck, J.S.; DenBaars, S.P.; Nakamura, S. Nonpolar III-nitride vertical-cavity surface-emitting laser with a photoelectrochemically etched air-gap aperture. Appl. Phys. Lett. 2016, 108, 031111. [CrossRef]

49. Forman, C.A.; Lee, S.; Young, E.C.; Kearns, J.A.; Cohen, D.A.; Leonard, J.T.; Margalith, T.; DenBaars, S.P.; Nakamura, S. Continuous-wave operation of m-plane GaN-based vertical-cavity surface-emitting lasers with a tunnel junction intracavity contact. Appl. Phys. Lett. 2018, 112, 111106. [CrossRef]

50. Lee, S.; Forman, C.A.; Lee, C.; Kearns, J.; Young, E.C.; Leonard, J.T.; Cohen, D.A.; Speck, J.S.; Nakamura, S.; Denbaars, S. GaNbased vertical-cavity surface-emitting lasers with tunnel junction contacts grown by metal-organic chemical vapor deposition. Appl. Phys. Express 2018, 11, 062703. [CrossRef]

51. Mishkat-Ul-Masabih, S.M.; Aragon, A.A.; Monavarian, M.; Luk, T.S.; Feezell, D.F. Electrically injected nonpolar GaN-based VCSELs with lattice-matched nanoporous distributed Bragg reflector mirrors. Appl. Phys. Express 2019, 12, 036504. [CrossRef]

52. Liu, W.-J.; Hu, X.-L.; Ying, L.-Y.; Zhang, J.-Y.; Zhang, B.-P. Room temperature continuous wave lasing of electrically injected GaN-based vertical cavity surface emitting lasers. Appl. Phys. Lett. 2014, 104, 251116. [CrossRef]

53. Xu, R.; Mei, Y.; Xu, H.; Yang, T.-R.; Ying, L.-Y.; Zheng, Z.-W.; Long, H.; Zhang, B.-P.; Liu, J. Effects of Lateral Optical Confinement in GaN VCSELs With Double Dielectric DBRs. IEEE Photon. J. 2020, 12, 1-8. [CrossRef]

54. Westbergh, P.; Gustavsson, J.S.; Haglund, Å.; Skold, M.; Joel, A.; Larsson, A. High-Speed, Low-Current-Density 850 nm VCSELs. IEEE J. Sel. Top. Quantum Electron. 2009, 15, 694-703. [CrossRef]

55. Khan, Z.; Ledentsov, N.; Chorchos, L.; Shih, J.-C.; Chang, Y.-H.; Shi, J.-W. Single-Mode 940 nm VCSELs With Narrow Divergence Angles and High-Power Performances for Fiber and Free-Space Optical Communications. IEEE Access 2020, 8, 72095-72101. [CrossRef]

56. Chaqmaqchee, F.; Lott, J. Impact of oxide aperture diameter on optical output power, spectral emission, and bandwidth for 980 nm VCSELs. OSA Contin. 2020, 3, 2602. [CrossRef]

57. Sirbu, A.; Iakovelv, V.; Mereuta, A.; Caliman, A.; Suruceanu, G.; Kapon, E. Wafer-fused heterostructures: Application to vertical cavity surface-emitting lasers emitting in the $1310 \mathrm{~nm}$ band. Semicond. Sci. Technol. 2010, 26, 014016. [CrossRef]

58. Muller, M.; Hofmann, W.; Grundl, T.; Horn, M.; Wolf, P.; Nagel, R.D.; Ronneberg, E.; Bohm, G.; Bimberg, D.; Amann, M.-C. 1550-nm High-Speed Short-Cavity VCSELs. IEEE J. Sel. Top. Quantum Electron. 2011, 17, 1158-1166. [CrossRef]

59. Alam, S.N.; Zubialevich, V.Z.; Ghafary, B.; Parbrook, P.J. Bandgap and refractive index estimates of InAlN and related nitrides across their full composition ranges. Sci. Rep. 2020, 10, 16205. [CrossRef]

60. Takeuchi, K.; Adachi, S.; Ohtsuka, K. Optical properties of $\mathrm{Al}_{\mathrm{x}} \mathrm{Ga}_{1-\mathrm{x}} \mathrm{N}$ alloy. J. Appl. Phys. 2010, 107, 023306. [CrossRef]

61. Antoinevincent, N.; Natali, F.; Mihailovic, M.; Vasson, A.M.; Leymarie, J.; Disseix, P.; Byrne, D.; Semond, F.; Massies, J. Determination of the refractive indices of $\mathrm{AlN}, \mathrm{GaN}$, and $\mathrm{Al}_{\mathrm{x}} \mathrm{Ga}_{1-\mathrm{x}} \mathrm{N}$ grown on (111)Si substrates. J. Appl. Phys. 2003, 93, 5222-5226. [CrossRef] 
62. Yu, G.; Wang, G.; Ishikawa, H.; Umeno, M.; Soga, T.; Egawa, T.; Watanabe, J.; Jimbo, T. Optical properties of wurtzite structure $\mathrm{GaN}$ on sapphire around fundamental absorption edge $(0.78-4.77 \mathrm{eV})$ by spectroscopic ellipsometry and the optical transmission method. Appl. Phys. Lett. 1997, 70, 3209-3211. [CrossRef]

63. Hashemi, E.; Bengtsson, J.; Gustavsson, J.; Stattin, M.; Cosendey, G.; Grandjean, N.; Haglund, A. Analysis of structurally sensitive loss in GaN-based VCSEL cavities and its effect on modal discrimination. Opt. Express 2014, 22, 411-426. [CrossRef]

64. Redondo-Cubero, A.; Lorenz, K.; Gago, R.; Franco, N.; Poisson, M.-A.D.F.; Alves, E.; Muñoz, E. Depth-resolved analysis of spontaneous phase separation in the growth of lattice-matched AlInN. J. Phys. D Appl. Phys. 2010, 43, 055406. [CrossRef]

65. Zhou, L.; Smith, D.J.; McCartney, M.R.; Katzer, D.S.; Storm, D.F. Observation of vertical honeycomb structure in InAlN/GaNInAlN/GaN heterostructures due to lateral phase separation. Appl. Phys. Lett. 2007, 90, 081917. [CrossRef]

66. Perillat-Merceroz, G.; Cosendey, G.; Carlin, J.-F.; Butte, R.; Grandjean, N. Intrinsic degradation mechanism of nearly latticematched InAlN layers grown on GaN substrates. J. Appl. Phys. 2013, 113, 063506. [CrossRef]

67. Lobanova, A.; Segal, A.; Yakovlev, E.; Talalaev, R. AlInN MOVPE: Growth chemistry and analysis of trends. J. Cryst. Growth 2012, 352, 199-202. [CrossRef]

68. Berger, C.; Dadgar, A.; Bläsing, J.; Lesnik, A.; Veit, P.; Schmidt, G.; Hempel, T.; Christen, J.; Krost, A.; Strittmatter, A. Growth of AlInN/GaN distributed Bragg reflectors with improved interface quality. J. Cryst. Growth 2015, 414, 105-109. [CrossRef]

69. Gadanecz, A.; Bläsing, J.; Dadgar, A.; Hums, C.; Krost, A. Thermal stability of metal organic vapor phase epitaxy grown AlInN. Appl. Phys. Lett. 2007, 90, 221906. [CrossRef]

70. Cosendey, G.; Carlin, J.-F.; Kaufmann, N.A.K.; Butte, R.; Grandjean, N. Strain compensation in AlInN/GaN multilayers on GaN substrates: Application to the realization of defect-free Bragg reflectors. Appl. Phys. Lett. 2011, 98, 181111. [CrossRef]

71. Carlin, J.-F.; Ilegems, M. High-quality AlInN for high index contrast Bragg mirrors lattice matched to GaN. Appl. Phys. Lett. 2003, 83, 668-670. [CrossRef]

72. Chen, D.; Xiao, H.; Han, J. Nanopores in GaN by electrochemical anodization in hydrofluoric acid: Formation and mechanism. J. Appl. Phys. 2012, 112, 064303. [CrossRef]

73. Zhang, C.; Park, S.H.; Chen, D.; Lin, D.-W.; Xiong, W.; Kuo, H.-C.; Lin, C.-F.; Cao, H.; Han, J. Mesoporous GaN for Photonic Engineering-Highly Reflective GaN Mirrors as an Example. ACS Photon. 2015, 2, 980-986. [CrossRef]

74. Lee, S.-M.; Gong, S.-H.; Kang, J.-H.; Ebaid, M.; Ryu, S.-W.; Cho, Y.-H. Optically pumped GaN vertical cavity surface emitting laser with high index-contrast nanoporous distributed Bragg reflector. Opt. Express 2015, 23, 11023-11030. [CrossRef] [PubMed]

75. Mishkat-Ul-Masabih, S.M.; Luk, T.S.; Monavarian, M.; Feezell, D.F. Polarization-pinned emission of a continuous-wave optically pumped nonpolar GaN-based VCSEL using nanoporous distributed Bragg reflectors. Opt. Express 2019, 27, 9495-9501. [CrossRef] [PubMed]

76. Stonas, A.R.; Margalith, T.; Denbaars, S.; Coldren, L.A.; Hu, E.L. Development of selective lateral photoelectrochemical etching of InGaN/GaN for lift-off applications. Appl. Phys. Lett. 2001, 78, 1945-1947. [CrossRef]

77. Haberer, E.; Sharma, R.; Stonas, A.R.; Nakamura, S.; DenBaars, S.P.; Hu, E.L. Removal of thick (>100 nm) InGaN layers for optical devices using band-gap-selective photoelectrochemical etching. Appl. Phys. Lett. 2004, 85, 762. [CrossRef]

78. Sharma, R.; Haberer, E.; Meier, C.; Hu, E.L.; Nakamura, S. Vertically oriented GaN-based air-gap distributed Bragg reflector structure fabricated using band-gap-selective photoelectrochemical etching. Appl. Phys. Lett. 2005, 87, 051107. [CrossRef]

79. Chen, L.-R.; Chen, B.-Y.; Kuo, S.-Y.; Hong, K.-B.; Lu, T.-C. Anti-guiding and guiding effects in GaN-based vertical-cavity surface-emitting lasers. AIP Adv. 2020, 10, 025204. [CrossRef]

80. Park, S.-H. Crystal Orientation Effects on Many-Body Optical Gain of Wurtzite InGaN/GaN Quantum Well Lasers. Jpn. J. Appl. Phys. 2003, 42, L170-L172. [CrossRef]

81. Park, S.-H.; Ahn, D. Optical polarization characteristics of m-plane InGaN/GaN quantum well structures and comparison with experiment. Appl. Phys. Lett. 2013, 103, 101107. [CrossRef]

82. Romanov, A.E.; Baker, T.J.; Nakamura, S.; Speck, J.S. ERATO/JST UCSB Group Strain-induced polarization in wurtzite III-nitride semipolar layers. J. Appl. Phys. 2006, 100, 023522. [CrossRef]

83. Kubota, M.; Okamoto, K.; Tanaka, T.; Ohta, H. Temperature dependence of polarized photoluminescence from nonpolar m-plane InGaN multiple quantum wells for blue laser diodes. Appl. Phys. Lett. 2008, 92, 011920. [CrossRef]

84. You, S.; Detchprohm, T.; Zhu, M.; Hou, W.; Preble, E.A.; Hanser, D.; Paskova, T.; Wetzel, C. Highly Polarized Green Light Emitting Diode inm-Axis GaInN/GaN. Appl. Phys. Express 2010, 3, 102103. [CrossRef]

85. Kyono, T.; Yoshizumi, Y.; Enya, Y.; Adachi, M.; Tokuyama, S.; Ueno, M.; Katayama, K.; Nakamura, T. Optical Polarization Characteristics of InGaN Quantum Wells for Green Laser Diodes on Semi-Polar $\{20 \backslash$ bar21 $\}$ GaN Substrates. Appl. Phys. Express 2010, 3, 011003. [CrossRef]

86. Huang, M.C.; Zhou, Y.; Chang-Hasnain, C.J. A surface-emitting laser incorporating a high-index-contrast subwavelength grating. Nat. Photon. 2007, 1, 119-122. [CrossRef]

87. Mateus, C.F.R.; Huang, M.C.Y.; Chen, L.; Changhasnain, C.J.; Suzuki, Y. Broad-Band Mirror (1.12-1.62 $\mu \mathrm{m})$ Using a Subwavelength Grating. IEEE Photon. Technol. Lett. 2004, 16, 1676-1678. [CrossRef]

88. Karagodsky, V.; Sedgwick, F.G.; Chang-Hasnain, C.J. Theoretical analysis of subwavelength high contrast grating reflectors. Opt. Express 2010, 18, 16973-16988. [CrossRef] 
89. Huang, S.-C.; Hong, K.-B.; Li, H.; Lu, T.-C. Metallic subwavelength grating on GaN-based edge emitting lasers. In Proceedings of the 2015 International Conference on Numerical Simulation of Optoelectronic Devices (NUSOD), Taipei, Taiwan, 7-11 September 2015; pp. 135-136.

90. Chang, T.-C.; Kuo, S.-Y.; Hashemi, E.; Haglund, Å.; Lu, T.-C. Lasing action in GaN-based VCSELs with top high-contrast grating reflectors. In Proceedings of the International Semiconductor Laser Conference (ISLC), Santa Fe, NM, USA, 16-19 September 2018; pp. 1-2.

91. Chang, T.-C.; Hong, K.-B.; Kuo, S.-Y.; Lu, T.-C. Demonstration of polarization control GaN-based micro-cavity lasers using a rigid high-contrast grating reflector. Sci. Rep. 2019, 9, 13055. [CrossRef]

92. Siekacz, M.; Muziol, G.; Hajdel, M.; Żak, M.; Nowakowski-Szkudlarek, K.; Turski, H.; Sawicka, M.; Wolny, P.; FeduniewiczŻmuda, A.; Stanczyk, S.; et al. Stack of two III-nitride laser diodes interconnected by a tunnel junction. Opt. Express 2019, 27, 5784-5791. [CrossRef]

93. Yonkee, B.P.; Young, E.C.; Lee, C.; Leonard, J.T.; Denbaars, S.; Speck, J.S.; Nakamura, S. Demonstration of a III-nitride edgeemitting laser diode utilizing a GaN tunnel junction contact. Opt. Express 2016, 24, 7816-7822. [CrossRef]

94. Zhao, Y.; Wu, F.; Huang, C.-Y.; Kawaguchi, Y.; Tanaka, S.; Fujito, K.; Speck, J.S.; Denbaars, S.; Nakamura, S. Suppressing void defects in long wavelength semipolar $\left(202^{-} 1^{-}\right)$InGaN quantum wells by growth rate optimization. Appl. Phys. Lett. 2013, 102, 091905. [CrossRef]

95. El-Masry, N.A.; Piner, E.L.; Liu, S.X.; Bedair, S.M. Phase separation in InGaN grown by metalorganic chemical vapor deposition. Appl. Phys. Lett. 1998, 72, 40-42. [CrossRef]

96. Müller, M.; Smith, G.; Gault, B.; Grovenor, C. Phase separation in thick InGaN layers-A quantitative, nanoscale study by pulsed laser atom probe tomography. Acta Mater. 2012, 60, 4277-4285. [CrossRef]

97. Hardy, M.T.; Wu, F.; Huang, C.-Y.; Zhao, Y.; Feezell, D.F.; Nakamura, S.; Speck, J.S.; Denbaars, S. Impact of p-GaN Thermal Damage and Barrier Composition on Semipolar Green Laser Diodes. IEEE Photon. Technol. Lett. 2013, 26, 43-46. [CrossRef]

98. Miyoshi, T.; Masui, S.; Okada, T.; Yanamoto, T.; Kozaki, T.; Nagahama, S.-I.; Mukai, T. 510-515 nm InGaN-Based Green Laser Diodes onc-Plane GaN Substrate. Appl. Phys. Express 2009, 2, 062201. [CrossRef]

99. Adachi, M.; Yoshizumi, Y.; Enya, Y.; Kyono, T.; Sumitomo, T.; Tokuyama, S.; Takagi, S.; Sumiyoshi, K.; Saga, N.; Ikegami, T.; et al. Low Threshold Current Density InGaN Based 520-530 nm Green Laser Diodes on Semi-Polar $\{20 \backslash$ bar21\} Free-Standing GaN Substrates. Appl. Phys. Express 2010, 3, 121001. [CrossRef]

100. Frost, T.; Banerjee, A.; Sun, K.; Chuang, S.L.; Bhattacharya, P. InGaN/GaN Quantum Dot Red ( $\lambda=630$ nm) Laser. IEEE J. Quantum Electron. 2013, 49, 923-931. [CrossRef]

101. Huang, C.-Y.; Walde, S.; Tsai, C.-L.; Netzel, C.; Liu, H.-H.; Hagedorn, S.; Wu, Y.-R.; Fu, Y.-K.; Weyers, M.; Sebastian, W. Overcoming the excessive compressive strain in AlGaN epitaxy by introducing high Si-doping in AlN templates. Jpn. J. Appl. Phys. 2020, 59, 070904. [CrossRef]

102. Dycus, J.H.; Washiyama, S.; Eldred, T.B.; Guan, Y.; Kirste, R.; Mita, S.; Sitar, Z.; Collazo, R.; Lebeau, J.M. The role of transient surface morphology on composition control in AlGaN layers and wells. Appl. Phys. Lett. 2019, 114, 031602. [CrossRef]

103. Kneissl, M.; Treat, D.W.; Teepe, M.; Miyashita, N.; Johnson, N.M. Ultraviolet AlGaN multiple-quantum-well laser diodes. Appl. Phys. Lett. 2003, 82, 4441-4443. [CrossRef]

104. Yoshida, H.; Yamashita, Y.; Kuwabara, M.; Kan, H. A 342-nm ultraviolet AlGaN multiple-quantum-well laser diode. Nat. Photon. 2008, 2, 551-554. [CrossRef]

105. Yoshida, H.; Yamashita, Y.; Kuwabara, M.; Kan, H. Demonstration of an ultraviolet $336 \mathrm{~nm}$ AlGaN multiple-quantum-well laser diode. Appl. Phys. Lett. 2008, 93, 241106. [CrossRef]

106. Zhang, Z.; Kushimoto, M.; Sakai, T.; Sugiyama, N.; Schowalter, L.J.; Sasaoka, C.; Amano, H. A 271.8 nm deep-ultraviolet laser diode for room temperature operation. Appl. Phys. Express 2019, 12, 124003. [CrossRef]

107. Hjort, F.; Enslin, J.; Cobet, M.; Bergmann, M.A.; Gustavsson, J.; Kolbe, T.; Knauer, A.; Nippert, F.; Häusler, I.; Wagner, M.R.; et al. A $310 \mathrm{~nm}$ Optically Pumped AlGaN Vertical-Cavity Surface-Emitting Laser. ACS Photon. 2021, 8, 135-141. [CrossRef]

108. Zhang, C.; El Afandy, R.T.; Zhang, J.; Chen, S.; Nurmikko, A.; Han, J. Development of nanopore-based near ultraviolet verticalcavity surface emitting lasers. In Proceedings of the Gallium Nitride Materials and Devices XIV, San Francisco, CA, USA, 4-7 February 2019; International Society for Optics and Photonics: Bellingham, WA, USA, 2019; Volume 10918, p. 109181M.

109. Liu, Y.-S.; Haq, A.F.M.S.; Mehta, K.; Kao, T.-T.; Wang, S.; Xie, H.; Shen, S.-C.; Yoder, P.D.; Ponce, F.; Detchprohm, T.; et al. Optically pumped vertical-cavity surface-emitting laser at $374.9 \mathrm{~nm}$ with an electrically conducting n-type distributed Bragg reflector. Appl. Phys. Express 2016, 9, 111002. [CrossRef]

110. Yeh, T.-W.; Lin, Y.-T.; Stewart, L.S.; Dapkus, P.D.; Sarkissian, R.; O’Brien, J.D.; Ahn, B.; Nutt, S.R. InGaN/GaN Multiple Quantum Wells Grown on Nonpolar Facets of Vertical GaN Nanorod Arrays. Nano Lett. 2012, 12, 3257-3262. [CrossRef]

111. Huang, C.-Y.; Tai, T.-Y.; Hong, K.-B.; Kuo, H.-C.; Lu, T.-C. Analysis of Quality Factor Enhancement in the Monolithic InGaN/GaN Nanorod Array. Appl. Sci. 2019, 9, 1295. [CrossRef]

112. Huang, C.-Y.; Lin, J.-J.; Chang, T.-C.; Liu, C.-Y.; Tai, T.-Y.; Hong, K.-B.; Lu, T.-C.; Kuo, H.-C. Collective Lasing Behavior of Monolithic GaN-InGaN Core-Shell Nanorod Lattice under Room Temperature. Nano Lett. 2017, 17, 6228-6234. [CrossRef]

113. Huang, C.-Y.; Lin, J.-J.; Chang, T.-C.; Liu, C.-Y.; Dai, T.-Y.; Hong, K.-B.; Lu, T.-C.; Kuo, H.-C. Monolithic GaN-InGaN Core-shell Lasers in Submicron Scale. In Proceedings of the Conference on Lasers and Electro-Optics, San Jose, CA, USA, 14-19 May 2017; The Optical Society: Washington, DC, USA, 2017; p. STh1C.2. 
114. Ra, Y.-H.; Lee, C.-R. Ultracompact display pixels: Tunnel junction nanowire photonic crystal laser. Nano Energy 2021, 84, 105870. [CrossRef]

115. Deng, H.; Weihs, G.; Snoke, D.; Bloch, J.; Yamamoto, Y. Polariton lasing vs. photon lasing in a semiconductor microcavity. Proc. Natl. Acad. Sci. USA 2003, 100, 15318-15323. [CrossRef]

116. Schneider, C.; Rahimi-Iman, A.; Kim, N.Y.; Fischer, J.; Savenko, I.; Amthor, M.; Lermer, M.; Wolf, A.; Worschech, L.; Kulakovskii, V.D.; et al. An electrically pumped polariton laser. Nat. Cell Biol. 2013, 497, 348-352. [CrossRef]

117. Bhattacharya, P.; Xiao, B.; Das, A.; Bhowmick, S.; Heo, J. Solid State Electrically Injected Exciton-Polariton Laser. Phys. Rev. Lett. 2013, 110, 206403. [CrossRef]

118. Tao, R.; Kamide, K.; Arita, M.; Kako, S.; Arakawa, Y. Room-Temperature Observation of Trapped Exciton-Polariton Emission in GaN/AlGaN Microcavities with Air-Gap/III-Nitride Distributed Bragg Reflectors. ACS Photon. 2016, 3, 1182-1187. [CrossRef]

119. Ciers, J.; Roch, J.G.; Carlin, J.-F.; Jacopin, G.; Butte, R.; Grandjean, N. Propagating Polaritons in III-Nitride Slab Waveguides. Phys. Rev. Appl. 2017, 7, 034019. [CrossRef]

120. Ciers, J.; Solnyshkov, D.D.; Callsen, G.; Kuang, Y.; Carlin, J.-F.; Malpuech, G.; Butté, R.; Grandjean, N. Polariton relaxation and polariton nonlinearities in nonresonantly cw-pumped III-nitride slab waveguides. Phys. Rev. B 2020, 102, 155304. [CrossRef]

121. Bhattacharya, P.; Frost, T.; Deshpande, S.; Baten, Z.; Hazari, A.; Das, A. Room Temperature Electrically Injected Polariton Laser. Phys. Rev. Lett. 2014, 112, 236802. [CrossRef] 